\title{
Three-body fragmentation dynamics of amidogen and methylene radicals via dissociative recombination
}

\author{
R. D. Thomas, ${ }^{*}$ F. Hellberg, A. Neau, S. Rosén, and M. Larsson \\ Department of Physics, Albanova, Stockholm University, SE106 91 Stockholm, Sweden \\ C. R. Vane, M. E. Bannister, and S. Datz \\ Physics Division, Oak Ridge National Laboratory, P.O. Box 2008, Oak Ridge, Tennessee 37831-6377, USA
}

A. Petrignani and W. J. van der Zande ${ }^{\dagger}$

FOM Instituut AMOLF, Kruislaan 407, 1098 SJ Amsterdam, The Netherlands

(Received 13 January 2004; published 14 March 2005)

\begin{abstract}
We report the investigation into the three-body fragmentation of the triatomic molecules $\mathrm{NH}_{2}$ and $\mathrm{CH}_{2}$ via the process of dissociative recombination (DR). Recently reported analysis of experiments into the DR of the similar system $\mathrm{H}_{2} \mathrm{O}$ indicated that the DR process is violent, involving a large degree of geometrical change and energy distribution from the initial attachment of the free electron by the parent ion to the final dissociation step. Comparison of data from $\mathrm{NH}_{2}$ and $\mathrm{CH}_{2}$ with that of $\mathrm{H}_{2} \mathrm{O}$ gives a similar picture of the DR process, though there are significant differences in the results, not only in the branching fraction between the expected decay channels, but also in the distribution of the available reaction energy over the product hydrogen atoms as well as in the molecular geometry at the point of dissociation.
\end{abstract}

DOI: 10.1103/PhysRevA.71.032711

PACS number(s): 34.80.Ht, 33.15.Bh, 33.15.Dj, 82.20.Fd

\section{INTRODUCTION}

Molecules containing carbon and nitrogen are some of the most important species in many areas of science, ranging from laser physics to combustion, interstellar chemistry, and biology. Carbon and carbon containing molecules play some of the biggest roles in interstellar chemical physics. For example, the production of carbon in stellar interiors via the triple- $\alpha$ process is one of the most important reactions in astrophysics, since without this process it is not possible to create atoms heavier than helium. Furthermore, in studies of molecular clouds, atomic carbon ions are used to determine the electron number density as this cannot be determined directly [1]. These data are then used to determine the column densities of critical species such as $\mathrm{H}_{3}^{+}$[2-4]. Molecular species containing carbon also play critical roles in planetary atmospheres, with methane and its methyl and methylene radicals being of considerable importance in the Jovian and Saturnian atmospheres [5].

For nitrogen, some of the most important species belong to the ammonia family, i.e., $\mathrm{NH}_{3}, \mathrm{NH}_{2}$ and $\mathrm{NH}$. The $\mathrm{NH}_{2}$ radical is important not only for testing the production pathways of nitrogen containing molecules, but also for its role in processes such as electrical discharge in ammonia [6], a role indicated by the $\alpha$ bands [7] in spectra obtained from such a process. These bands are also significant in astrochemistry, since they are a major spectroscopic signature in cometary atmospheres. $\mathrm{NH}_{2}$ was suggested to be an important con-

\footnotetext{
*Author to whom correspondence should be addressed. Electronic address: rdt@physto.se

†Present address: Department of Physics, University of Nijmegen, 6525 ED Nijmegen, The Netherlands.
}

stituent in such regions [8-10], though it was only in 1993, when van Dishoeck and co-workers detected $\mathrm{NH}_{2}$ in interstellar space [11], that its pivotal role was confirmed. Furthermore, $\mathrm{NH}_{2}$ has also been suggested [12] to play an important role in the production of $\mathrm{NH}$, whose spectroscopic signature has also been observed in these environments $[13,14]$.

In many regions which contain such molecular species there is a high degree of ionization and, as such, there is a constant production of ions and electrons. That there is a significant degree of ionization is highly important, as one of the most efficient neutralization processes for molecular ions is dissociative recombination.

Dissociative recombination (DR) is a reaction process in which a molecular ion recombines with a low-energy electron, with the resulting intermediate then fragmenting into neutral products taking away the excess internal energy. DR is an extremely important mechanism in controlling the ionization level of many media and results not only in the loss of molecular ionic species but also in the production of different, mainly radical, neutral species (see, e.g., Refs. [15-17]). The rate coefficients and neutral product branching fractions arising from such processes are necessary for understanding these environments.

One successful experimental technique extensively utilized to study DR reactions is the ion storage ring. The use and scope of ion storage rings in DR studies has been covered in depth in many reviews, with two of the most recent being Refs. [18,19]. Of particular relevance, recent advances in detector technology have enabled the accurate measurement of the kinetic energy of the neutral fragments following the DR of molecular ions (see, e.g., Refs. [20-25]).

The apparent simplicity of the DR process belies the difficulty in developing a general theory which is able to predict 
product branching fractions for polyatomic ions. There have been relatively few attempts at a theoretical approach to understanding such mechanisms. The oldest models, developed by Bates $[26,27]$ argue that the most favored dissociative channel is that which involves the least re-arrangement of valence bonds in the molecule. This theory then predicts that for ions of the type $X \mathrm{H}_{2}^{+}\left(\mathrm{H}_{2} X^{+}\right)$, the most favored dissociation channel is likely to involve the loss of a single hydrogen atom. However, to date all storage ring studies on the DR of $X \mathrm{H}_{n}^{+}$-type ions show a propensity for three-body breakup. In collisions of zero $\mathrm{eV}$ electrons with the ions $\mathrm{H}_{3}^{+}$[28], $\mathrm{CH}_{2}^{+}$ [29], $\mathrm{NH}_{2}^{+}$[30], and $\mathrm{H}_{2} \mathrm{O}^{+}$[31] the three-body DR channel constitutes $60-80 \%$ of the reaction products.

This observation of the dominance of the three-body fragmentation channel from the DR of these species has, in the last two years, led to more detailed investigations, discussed in a recent review article [32]. Up to now, experimental data and theoretical descriptions have been reported for two species in particular, $\mathrm{H}_{2} \mathrm{O}^{+}$and $\mathrm{H}_{3}^{+}$. The initial observations for $\mathrm{H}_{2} \mathrm{O}^{+}$, reported by Datz et al. [24], were investigated using a model developed by Dixon et al., see, e.g., Ref. [33]. The results from this analysis and its comparison with the experimental observations were reported by Thomas et al. [25]. They concluded that multiple fragmentation was, indeed, the dominant channel and a natural outcome of the model, and not due to any unphysical constraint or assumptions of the model. For $\mathrm{H}_{3}^{+}$, Strasser and co-workers developed a concise statistical model [34] in an attempt to explain the experimental observations reported by Datz et al. [28]. The results from their model were in excellent agreement with the experimental observations up to collision energies of several $\mathrm{eV}$.

In the work reported here, we have extended investigations of $\mathrm{H}_{2} \mathrm{O}^{+}$to studies of DR of $\mathrm{NH}_{2}^{+}$and $\mathrm{CH}_{2}^{+}$. In the main focus of this work, we report data on the competition among the available three-body fragmentation channels and, using the experience obtained from the earlier analysis of $\mathrm{H}_{2} \mathrm{O}^{+}$, try to understand the dynamic processes occurring. Finally, due to a difference in the branching pattern reported from an earlier experiment at CRYRING on $\mathrm{NH}_{2}^{+}$[30], compared with the patterns for other ions of the type $\mathrm{XH}_{2}^{+}$, an improved experimental setup was used to re-investigate the fragmentation for $\mathrm{NH}_{2}^{+}$.

\section{EXPERIMENTAL SYSTEMS}

For collisions between $0 \mathrm{eV}$ electrons and $\mathrm{NH}_{2}^{+}$and $\mathrm{CH}_{2}^{+}$, Table I lists the available dissociation channels, together with their respective kinetic release energies and, for the threebody product channels, the possible electronic excitation states of the heavy fragment, i.e., $\mathrm{N}$ and $\mathrm{C}$, are also given. The quoted $\mathrm{NH}_{2}^{+}$reaction energies were calculated using the latest measurement of the $\mathrm{NH}_{2}$ ionization energy [35] while those for $\mathrm{CH}_{2}^{+}$were calculated from data in the NIST database [36].

The $\mathrm{DR}$ of $\mathrm{NH}_{2}^{+}$at $0 \mathrm{eV}$ has three available reaction channels, producing $\mathrm{NH}+\mathrm{H}, \mathrm{N}+\mathrm{H}_{2}$, and $\mathrm{N}+2 \mathrm{H}$, respectively, and are denoted as channels (1)-(3). The latter of these reactions creates two $\left({ }^{2} S\right) \mathrm{H}$ atoms together with either ground $\left({ }^{4} S\right)$, first $\left({ }^{2} D\right)$, or second $\left({ }^{2} P\right)$ excited state $\mathrm{N}$ atoms, denoted as
TABLE I. List of relevant dissociation channels for collisions of $\mathrm{NH}_{2}^{+}$and $\mathrm{CH}_{2}^{+}$with $0 \mathrm{eV}$ electrons. The available kinetic energy is given for each channel assuming that any molecular products are formed in their electronic and rovibrational ground states. For the three body channels, 3(a)-3(c), and 4(a) and 4(b), the electronic state of the heavy atom is also indicated. The energetics for $\mathrm{NH}_{2}^{+}$ were calculated using the latest ionization energy for $\mathrm{NH}_{2}$ reported by Dyke [35], while the energetics for $\mathrm{CH}_{2}^{+}$were obtained using the available data on the NIST webbook [36].

\begin{tabular}{cccc}
\hline \hline Ion & Neutral channel & State and energy & Channel number \\
\hline $\mathrm{NH}_{2}^{+}$ & $\mathrm{NH}+\mathrm{H}$ & $6.97 \mathrm{eV}$ & 1 \\
& $\mathrm{~N}+\mathrm{H}_{2}$ & $8.24 \mathrm{eV}$ & 2 \\
& $\mathrm{~N}+\mathrm{H}+\mathrm{H}$ & $\mathrm{N}\left({ }^{4} \mathrm{~S}\right), 3.72 \mathrm{eV}$ & $3(\mathrm{a})$ \\
& & $\mathrm{N}\left({ }^{2} \mathrm{D}\right), 1.34 \mathrm{eV}$ & $3(\mathrm{~b})$ \\
& $\mathrm{N}\left({ }^{2} \mathrm{P}\right), 0.14 \mathrm{eV}$ & $3(\mathrm{c})$ \\
$\mathrm{CH}_{2}^{+}$ & $\mathrm{C}+\mathrm{H}+\mathrm{H}$ & $\mathrm{C}\left({ }^{3} \mathrm{P}\right), 2.45 \mathrm{eV}$ & $4(\mathrm{a})$ \\
& & $\mathrm{C}\left({ }^{1} \mathrm{D}\right), 1.19 \mathrm{eV}$ & $4(\mathrm{~b})$ \\
\hline \hline
\end{tabular}

channels 3(a)-3(c), respectively. It is noted that the low kinetic energy $(0.14 \mathrm{eV})$ available to the fragments in channel $3(c)$ might preclude their detection in the current experiment. For $\mathrm{CH}_{2}^{+}$, together with the two $\left({ }^{2} S\right) \mathrm{H}$ atoms, there is sufficient energy to form either ground $\left({ }^{3} P\right)$ or first excited $\left({ }^{1} D\right)$ state $\mathrm{C}$ atoms, denoted 4(a) and 4(b), respectively. Both channels have sufficient kinetic energy to be detected.

\section{EXPERIMENT}

The experiments have been performed at the heavy-ion storage ring CRYRING at the Manne Siegbahn Laboratory, Stockholm University. The facility and experimental procedures have been described in detail elsewhere $[18,19,25]$, and are summarized only briefly here. Figure 1 illustrates the layout of the CRYRING apparatus. The ions were produced in a hot filament Penning discharge source, $\mathrm{NH}_{2}^{+}$from ammonia, and $\mathrm{CH}_{2}^{+}$from methane. After extraction of the ions from the source at $40 \mathrm{keV}$, they were mass selected, injected into the ring, and accelerated to the required storage energy. For the chemical-branching experiment the $\mathrm{NH}_{2}^{+}$beam energy was $6.0 \mathrm{MeV}$. For the imaging experiments a beam energy of $250 \mathrm{keV} / \mathrm{amu}$ was used, i.e., 4.0 and $3.5 \mathrm{MeV}$ for $\mathrm{NH}_{2}^{+}$and $\mathrm{CH}_{2}^{+}$respectively. The reason for using $250 \mathrm{keV} / \mathrm{amu}$ is discussed in detail in Ref. [25]. The stored ion beam was merged with a monoenergetic electron beam in the electron cooler, the interaction length being $\approx 0.85 \mathrm{~m}$. During the first $4 \mathrm{~s}$ after acceleration the electron and ion beams were kept at the same average velocity, to allow heat transfer from the ions to the electrons, in order to reduce the translational temperature of the ions which results in an increase of their phase-space density. Furthermore, such storage times also enable radiative vibrational cooling of the ions. The electron beam also served as a source of electrons for the DR process.

Neutral products created in the cooler region were separated from the ion beam as they passed through the first ring 


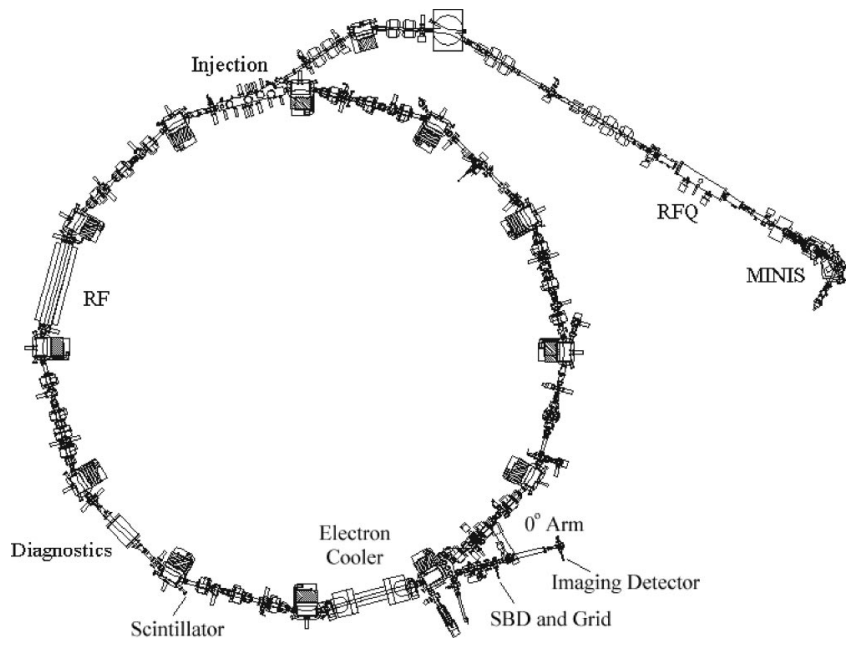

FIG. 1. Layout of the storage ring facility CRYRING. Ions are created in a hot filament ion source, MINIS, with a $90^{\circ}$ separator magnet used for mass selection. The mass selected ions are then injected in the ring at $40 \mathrm{keV}$ and accelerated further to the required beam energy, either $6.00 \mathrm{MeV}$ for the $\mathrm{NH}_{2}^{+}$experiment involving the surface barrier detector (SBD) and grid, or to $250 \mathrm{keV} / \mathrm{amu}$ for the $\mathrm{NH}_{2}^{+}$and $\mathrm{CH}_{2}^{+}$experiments with the imaging detector. In the electron cooler section the ions interact with electrons, the neutral products enter the $0^{\circ}$ arm and are detected. Monitoring of the number of $\mathrm{NH}_{2}^{+}$ions in the beam, required for the work with the SBD, is achieved using a scintillation detector positioned at the end of a straight section before the electron cooler.

dipole magnet following the cooler. A surface barrier detector $(\mathrm{SBD})$, located $\approx 4.0 \mathrm{~m}$ from the center of the interaction region, was used to investigate the chemical branching of $\mathrm{NH}_{2}^{+}$, a technique discussed in detail elsewhere (see, e.g., Refs. [28-31,37]). Located a further $2.3 \mathrm{~m}$ downstream of the interaction region is the position-sensitive multihit detector array used to investigate the three-body fragmentation. This technique is also discussed in some detail in the literature [20-25]. It was not possible to use both detection systems simultaneously, and the SBD was retracted from the detection region for the three-body dynamics measurements.

\section{A. Investigating the branching fractions}

The neutral particles from the DR event are monitored by a SBD, the output of which, read by a multichannel analyzer (MCA) card, is proportional to the energy dissipated in the active region of the detector. Each fragment carries an energy proportional to its mass. Detecting all of the fragments from a DR event gives a maximum output signal corresponding to the full-beam energy of the stored molecular ion. A lower signal thus corresponds to the detection of fewer fragments. Since the fragments from a single DR event arrive within the integration time of the detector, the signal arising from an $\mathrm{NH}$ fragment will be indistinguishable from separated $\mathrm{N}$ and $\mathrm{H}$ fragments. Using a technique successfully utilized by Berkner et al. [38] and applied to studies at storage rings by Datz et al. [28], a stainless steel grid, $50 \mu \mathrm{m}$ thick and containing holes of $84 \mu \mathrm{m}$ diameter [39] is situated in front of the SBD. The grid has a known, independently measured, transmission $T=0.297 \pm 0.015$ (3 $\sigma$ uncertainty) [37]. The probability of a particle passing through the grid is $T$ and for it stopping in the grid is $(1-T)$. The number of counts in the different mass/energy peaks when the grid is removed versus when it is present is only related to the transmission of the grid and the relative populations of the available reaction channels. The branching among the available channels can then be solved numerically from the measured intensities of the different mass peaks.

The contribution to the detected counts arising from non-DR processes in the "electron cooler," for example, electron-capture reactions with rest gas $(R)$ molecules, typically $\mathrm{H}_{2}$ and $\mathrm{CH}_{4}$, must be determined, e.g.,

$$
\mathrm{NH}_{2}^{+}+R \rightarrow \mathrm{N}+\mathrm{H}+\mathrm{H}^{+}+R+E(\mathrm{eV})
$$

At the end of one of the straight sections before the electron cooler a scintillation detector, connected to a multichannel scaler (MCS), is used to monitor the neutral products arising from such interactions, the count rate being related to the number of ions in the stored beam.

Data from the [DR + background] and [background] processes in the electron cooler cannot be obtained at the same time. To account for the contribution of these [background] processes, the electron energy is tuned away from 0 to $1 \mathrm{eV}$. The cross section for DR at this energy is sufficiently small that the measured signal is mainly due to background processes. For each of these two situations, MCA data are acquired over a period of time corresponding to several hundred injection cycles until the statistical error in the data is acceptable. Simultaneously, the number of ions in the ring is monitored as described earlier. Combining these data sets, the [background] contribution to the [DR + background] signal can be obtained and accounted for.

The relationship between the observed peaks and the intensities of the available reaction channels is given by

$$
\left(\begin{array}{c}
N_{\mathrm{N}+2 \mathrm{H}-\mathrm{bkg}} \\
N_{\mathrm{N}+\mathrm{H}-\mathrm{bkg}} \\
N_{\mathrm{N}-\mathrm{bkg}} \\
N_{2 \mathrm{H}-\mathrm{bkg}} \\
N_{\mathrm{H}-\mathrm{bkg}}
\end{array}\right)=\left(\begin{array}{ccc}
T^{2} & T^{2} & T^{3} \\
0 & T(1-T) & 2 T^{2}(1-T) \\
T(1-T) & 0 & T(1-T)^{2} \\
T(1-T) & 0 & T^{2}(1-T) \\
0 & T(1-T) & 2 T(1-T)^{2}
\end{array}\right)\left(\begin{array}{l}
N_{1} \\
N_{2} \\
N_{3}
\end{array}\right)
$$

where $N_{\mathrm{N}+2 \mathrm{H}-\mathrm{bkg}}$, etc., corresponds to the background corrected counts in each of the peaks in the spectra. The branching fractions into channels (1)-(3), as listed in Table I, are obtained by normalizing the solutions for $N_{1}, N_{2}$, and $N_{3}$. For example,

$$
n_{i}=\frac{N_{i}}{\sum_{i=1}^{3} N_{i}}
$$

where $n_{i}$ corresponds to the fraction going into channel $i$. 


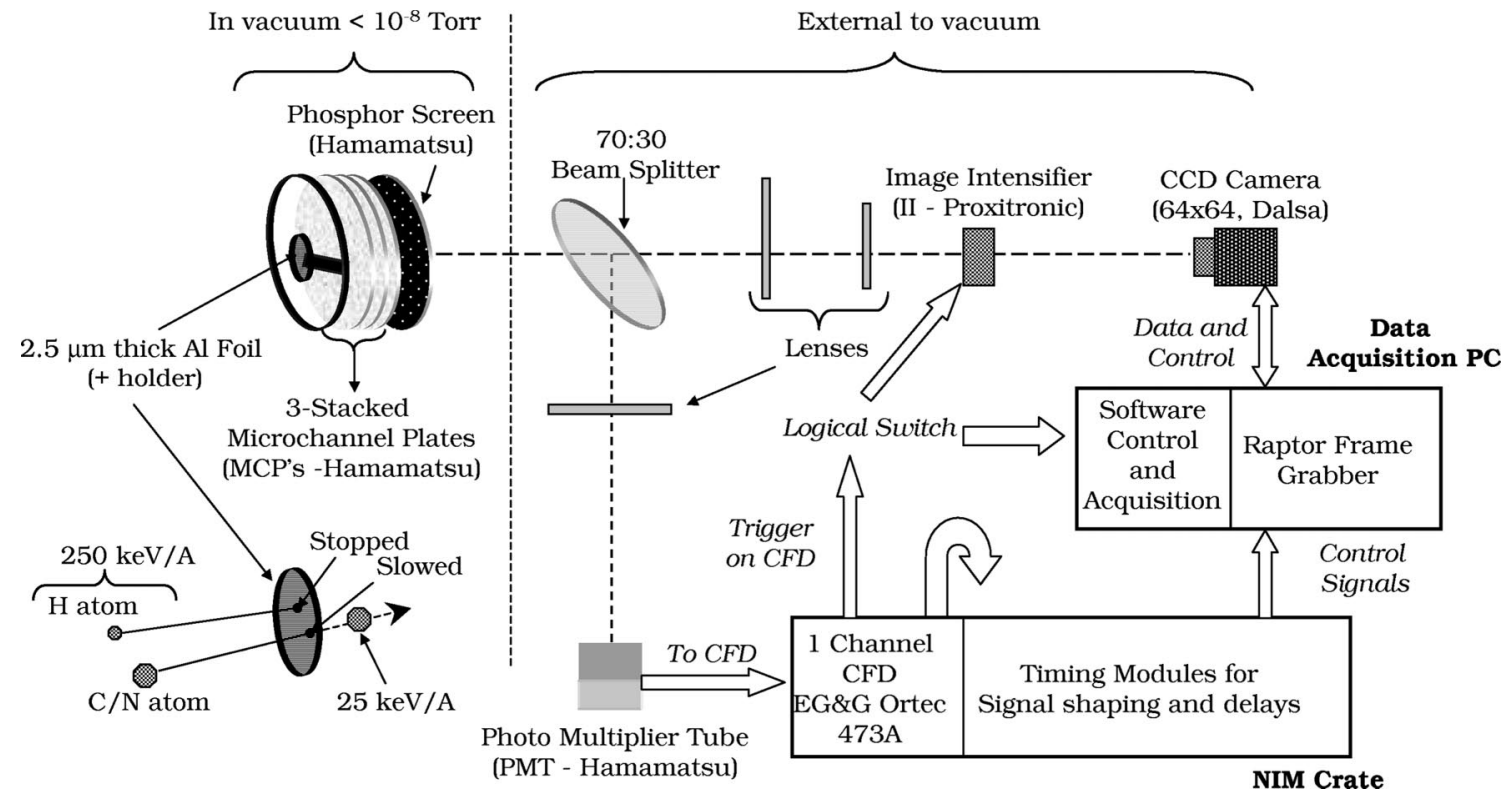

FIG. 2. Schematic of the detector and data acquisition system. Light emitted from the phosphor is split and focused onto a photo multiplier tube (PMT, Hamamatsu) and image intensifier (II, Proxitronic). Light from the output phosphor of the II is focused onto the CCD chip in the camera. The output from the PMT is shaped by a CFD and used as a trigger for the II and the RAPTor (BitFlow Inc.) frame-grabbing card which then reads the information on the CCD chip in the camera. The data acquisition computer controls the internal frame-grabbing card via local bus.

\section{B. Investigating the dynamics in three-body fragmentation}

A schematic of the position-sensitive imaging detection system $[23,25,40]$ used in this experiment is shown in Fig. 2. The neutral fragments from a DR event hit a stack of three microchannel plates (MCPs) followed by a phosphor screen. Light from the phosphor screen is split and imaged onto a photomultiplier tube (PMT) and, via an image intensifier (II), onto a charge-coupled device (CCD) camera. The PMT triggers the II and the CCD camera, the CCD recording an image of the phosphor screen. A software based spot-finding routine provides information about the positions of the detected flashes in the CCD frame. The interasting "neutralatom tagging" foil technique developed to differentiate between the heavier atomic fragment and hydrogen atom hits on the MCPs [25] was also used here, and so the spots found in the CCD frame can then be identified as to their fragment source. In previous experiments, mostly on diatomic molecules, a position- and time-sensitive detector has been successfully used $[22,23]$. However, when used in the DR of $\mathrm{H}_{2} \mathrm{O}^{+}$, it was clear that this arrangement did not have sufficient time resolution to allow such a clear selection to be made for multiple particle fragmentation [25]. As such, for the experiments reported here, data sets consisting only of particle positions were recorded.

DR event selection is based on the following criteria: that each CCD image contained three spots, and that one of the spots corresponds to the heavy atom fragment, i.e., it appears in the frame where the foil would be. Events fulfilling these criteria are then fully characterized and, for each event, the distances of the heavy and two $\mathrm{H}$ atoms from the center of mass (c.m.) were determined. Accepted events were analyzed for the following experimental parameters:

$$
T D=\left(d_{\mathrm{H}_{1}}^{2}+d_{\mathrm{H}_{2}}^{2}+\frac{m_{X}}{m_{\mathrm{H}}} d_{X}^{2}\right)^{1 / 2}
$$

where $d_{\mathrm{H}_{n}}$ and $d_{X}$ are the distances of the hydrogen atoms and the heavier atom from the c.m., respectively, and $m_{\mathrm{H}}$ and $m_{X}$ are the masses of the hydrogen and heavier atom fragments, respectively,

$$
\chi_{D}=\angle(\mathrm{H}-\mathrm{c} \cdot \mathrm{m} \cdot \mathrm{-H}),
$$

where $\chi_{D}$ is the H-c.m.-H angle measured in the plane of the detector with respect to the c.m., and

$$
P\left(\mathrm{c} . \mathrm{m} .-\mathrm{H}_{i}\right)
$$

which is the frequency distribution of $\mathrm{H}$ atom distances $(i$ $=1,2$ ) from the c.m., used to determine the partitioning of the available kinetic energy between the $\mathrm{H}$-atom fragments.

The displacements of the fragments from the c.m. in the laboratory frame reflect directly the projected momenta of the fragments in the molecular frame. "TD" (total displacement) then represents the energy measured in the plane of the detector, and this varies according to the extent of the motion out of the detector plane. The energy available in the process and the internal energy of the fragment atoms determines the kinetic energy release in the DR process, which is therefore directly related to the maximum possible TD. Production of an excited atomic fragment therefore means less available kinetic energy than for ground-state fragments and a smaller maximum TD. Increasing the energy available, either by changing the collision energy or the internal state of the parent ion, increases the maximum possible TD. It is noted that since TD is roughly linear in the total displacement of, in particular, the hydrogen atoms, the uncertainty is approxi- 


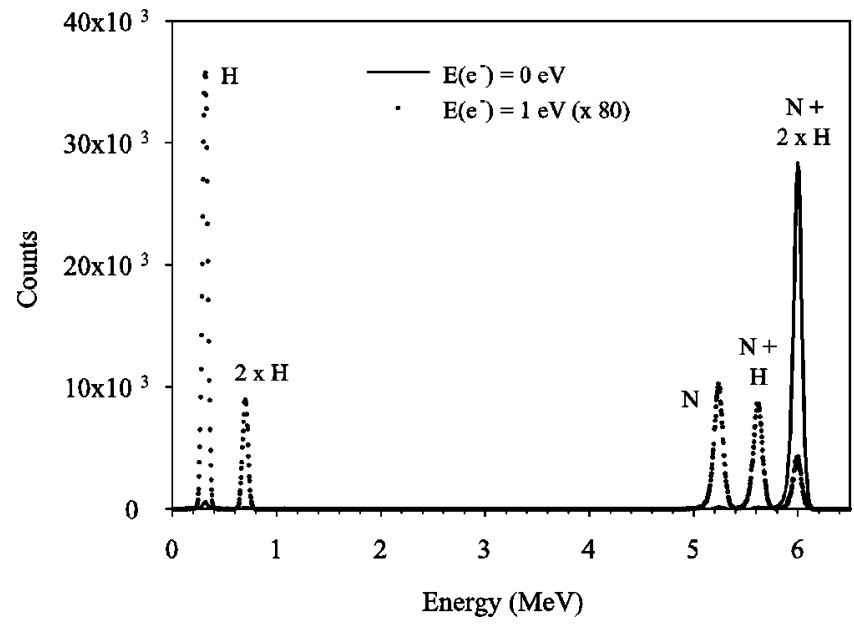

FIG. 3. Composite MCA spectra showing results for the chemical branching observed for the reaction $\mathrm{NH}_{2}^{+}+e^{-}$. Plotted are those raw MCA spectra obtained when the grid is out and where the electron beam is set to cooling (solid line) and tuned to $1 \mathrm{eV}(\mathbf{)})$, respectively. The masses of the fragments contributing to each peak are indicated.

mately independent of its magnitude, and determined by the quality of the imaging system. Finally, the demagnification factor between the phosphor screen and the CCD camera was determined for all of the imaging experiments reported here.

\section{EXPERIMENTAL RESULTS AND DISCUSSION}

The chemical branching from the $\mathrm{DR}$ of $\mathrm{NH}_{2}^{+}$and the competition between the three-body fragmentation channels open to $\mathrm{NH}_{2}^{+}$and $\mathrm{CH}_{2}^{+}$are discussed here. In each of these studies, data were taken at $0 \mathrm{eV}$ relative collision energy.

\section{A. Chemical branching}

The data sets used to determine the populations of the three available channels listed in Table I are plotted in Figs. 3 and 4. Figure 3 plots data obtained with the grid out. With the electrons at $0 \mathrm{eV}$ (solid line), the DR peak is defined and the energy scale calibrated. Those data obtained at $1 \mathrm{eV}$ (dotted line), corresponding to background processes, are clearly different from those arising from the DR process. Figure 4 plots the DR data $(\bigcirc)$, obtained with the partial transmission grid in and corrected for the background processes. The obtained best-fit solution to these data is also plotted (solid line) in Fig. 4, with the inset in Fig. 4 illustrating the accuracy of the fit. These data are then used to solve the matrix given in Eq. (2) for the $N_{i}$ values, and the branching fractions, obtained from Eq. (3), are calculated to be $n_{1}$ $=0.39(5), n_{2}=0.04(3)$, and $n_{3}=0.57(8)$.

It is noted that the system of equations represented in Eq. (2) is overdetermined since there are five peaks but only three reaction channels. Furthermore, as the total branching must sum to 1.00 only two of the three channels need to be solved. Different combinations of data were used to check the reliability of the results and to obtain the quoted uncertainties, typically at the $15 \%$ level (relative). The largest con-

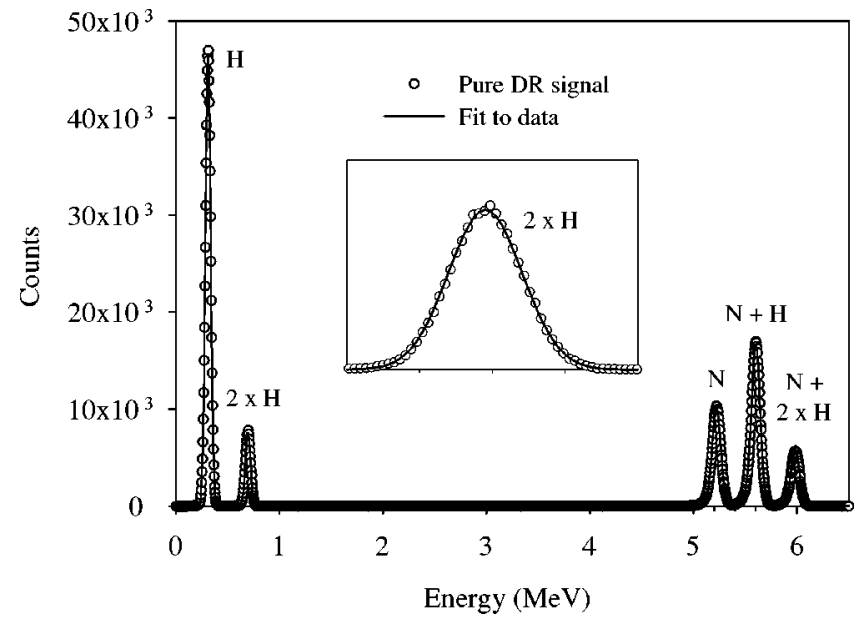

FIG. 4. Background-corrected MCA spectra obtained for the case where the grid is in and the electron beam is on $(O)$ The best fit to the curve is obtained using the branching ratio given in the main text, and the inset figure gives an indication of the goodness of the fit to these data, with the $2 \times \mathrm{H}$ peak taken as an example.

tribution to the uncertainty is the transmission factor of the grid [37].

These data correlate well with the earlier data [30] which reported no evidence of the $\mathrm{N}+\mathrm{H}_{2}$ channel. The current study finds only a $4 \%$ population of this channel, even after very careful analysis and without the partial detection difficulties encountered in the earlier study. Irrespective of the experimental uncertainties, this product channel is clearly unfavored and its weakness clearly indicates that $\mathrm{NH}_{2}$ behaves differently from both $\mathrm{H}_{2} \mathrm{O}$ and $\mathrm{CH}_{2}$, which fragment with an appreciable probability into their respective $\mathrm{O} / \mathrm{C}$ $+\mathrm{H}_{2}$ channel. Explanation of this observation may be related to the dynamics involved in the available reaction channels. The ground state of $\mathrm{NH}_{2}^{+}$is triplet in character meaning that the formation of $\mathrm{H}_{2}$ in the singlet bound state is perfectly allowed. That $\mathrm{H}_{2}$ is not observed to the same degree as it is in $\mathrm{H}_{2} \mathrm{O}$ and $\mathrm{CH}_{2}$ may indicate that the doublet states play a more prominent role in the initial capture step. Doublet states are highly unfavored for the production of singlet $\mathrm{H}_{2}$, and this would manifest itself in a decreased production of $\mathrm{N}$ $+\mathrm{H}_{2}$, and an increased production of $\mathrm{NH}+\mathrm{H}$ over that of $\mathrm{N}$ $+\mathrm{H}+\mathrm{H}$

\section{B. Electronic branching}

The TD distributions obtained for $\mathrm{NH}_{2}^{+}$are plotted in Fig. 5 . The quoted error bars are purely statistical. The vertical dashed lines indicate the calculated maximum TD for each of the available channels. The two observed maxima correlate with the channels producing $\mathrm{N}\left({ }^{2} D\right)$ and $\mathrm{N}\left({ }^{4} S\right)$. It is concluded with certainty that both of these channels are populated in the experiment. The lack of a local maxima in the TD distribution corresponding to the production of $\mathrm{N}\left({ }^{2} P\right)$ could indicate either a small probability for the production of $\mathrm{N}\left({ }^{2} P\right)$ or a low detection efficiency for this channel, due to the low kinetic energy available to the fragments. These possibilities are discussed later. 


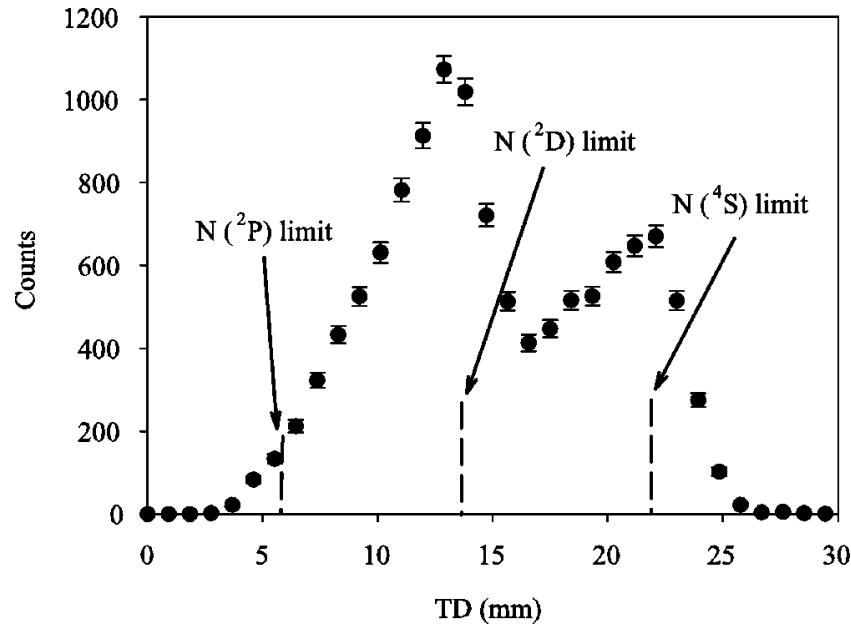

FIG. 5. The measured TD distribution of all the three-body fragments from the $\mathrm{DR}$ of $\mathrm{NH}_{2}^{+}$. Indicated on the figure are the limits for the three available channels leading to $\mathrm{N}\left({ }^{4} S\right), \mathrm{N}\left({ }^{2} D\right)$, and $\mathrm{N}\left({ }^{2} P\right)$, respectively.

Similar to Fig. 5, the TD data from the DR of $\mathrm{CH}_{2}^{+}$are plotted in Fig. 6. The observed maxima in the TD distribution correspond to those expected for the two available reaction channels producing $\mathrm{C}\left({ }^{3} P\right)$ and $\mathrm{C}\left({ }^{1} D\right)$. It is straightforward to conclude that both of these channels are significantly populated in the experiment. As for $\mathrm{NH}_{2}^{+}$, the quoted error bars are statistical.

As was observed in our earlier $\mathrm{H}_{2} \mathrm{O}^{+}$study [25], the individual TD distributions arising from individual reaction channels overlap. To obtain consistent values for these populations a Monte Carlo simulation modeling the asymptotic momentum of the fragments was developed. A similar approach was undertaken for the TD distributions obtained here.

It is worth noting that all of the measured TD distributions indicate that the molecule dissociates isotropically. In the DR of diatomic molecules with $0 \mathrm{eV}$ electrons, for which ana-

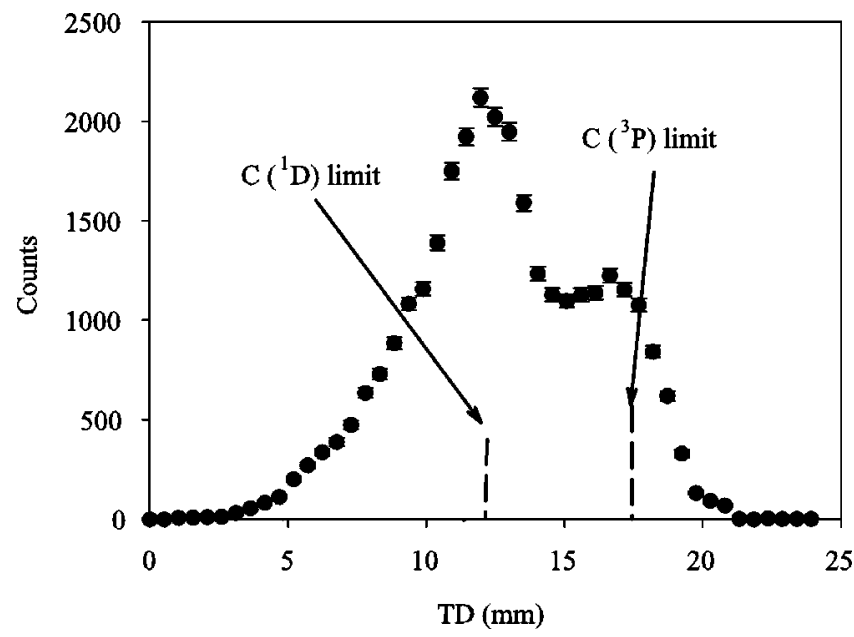

FIG. 6. The measured TD distribution of all the three-body fragments from the DR of $\mathrm{CH}_{2}^{+}$. Indicated on the figure are the maximum TD limits for the two available channels leading to $C\left({ }^{1} D\right)$ and $\mathrm{C}\left({ }^{3} P\right)$, respectively.

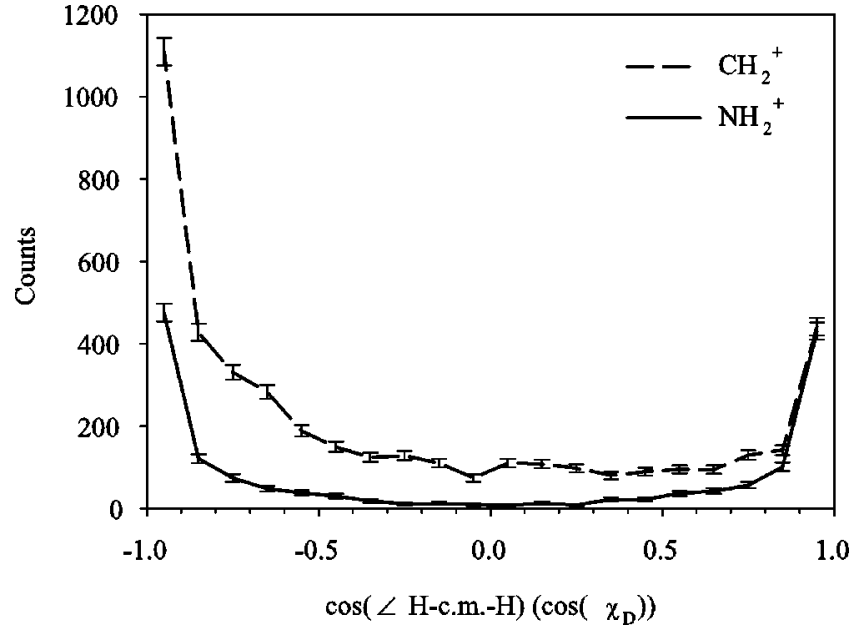

FIG. 7. The measured H-c.m.-H angular distribution of fragments from the $\mathrm{DR}$ of $\mathrm{NH}_{2}^{+}$(solid line) and $\mathrm{CH}_{2}^{+}$(dashed line) for selected events which have dissociated preferentially parallel to the detector.

lytical descriptions of the measured distance distributions exist, all experiments show an isotropic fragmentation. Importantly, this is not necessarily the case in collisions at energies greater than $0 \mathrm{eV}$.

\section{Angular distribution}

It is again noted that $0 \mathrm{eV}$ collisions are isotropic and that the molecular frame is randomly oriented with respect to the detector plane at dissociation. For each DR event the measured angle between the two hydrogen atoms and the center of mass is a projection of the dissociation opening angle in the molecular frame of reference. The approach employed here is to select and analyze only those events which have the greatest TD, since the majority of these molecules fragmented parallel to the detector plane, and the effect of the projection is a minimum. Several different cuts of the experimental data were made to investigate trends in the data. In using this approach, only those events producing ground state fragments, i.e., $\mathrm{N}\left({ }^{4} S\right)$ and $\mathrm{C}\left({ }^{3} P\right)$, are analyzed as these data are uncontaminated by contributions from the excited states $\mathrm{N}\left({ }^{2} P\right), \mathrm{N}\left({ }^{2} D\right)$, and $\mathrm{C}\left({ }^{1} D\right)$.

Figure 7 plots data for $\mathrm{NH}_{2}^{+}$(solid line) and $\mathrm{CH}_{2}^{+}$(dashed line) representing data with TDs greater than 21.0 and 17.5 $\mathrm{mm}$, respectively. There are significant differences between the distributions. The data for $\mathrm{CH}_{2}^{+}$show a much broader preference for an open angle geometry than those for $\mathrm{NH}_{2}^{+}$ which has a much sharper distribution and a preference for both an open and closed geometry. The error bars given in the figure are entirely statistical.

Both experimental and theoretical values for the equilibrium ground-state geometry of the triatomic dihydride ions $\mathrm{CH}_{2}^{+}, \mathrm{NH}_{2}^{+}$, and $\mathrm{H}_{2} \mathrm{O}^{+}$ions have been recently reported in the literature [41,42]. Table I in Ref. [41] presents a detailed overview of previous theoretical and experimental values of the standard parameters. Of relevance, the ground state $\left(X^{3} B_{1}\right)$ geometry of $\mathrm{NH}_{2}^{+}$has a minimum at $\approx 157 \pm 7^{\circ}\left[\cos \left(\chi_{D}\right)=-0.92 \pm 0.05\right]$ and the ground state 


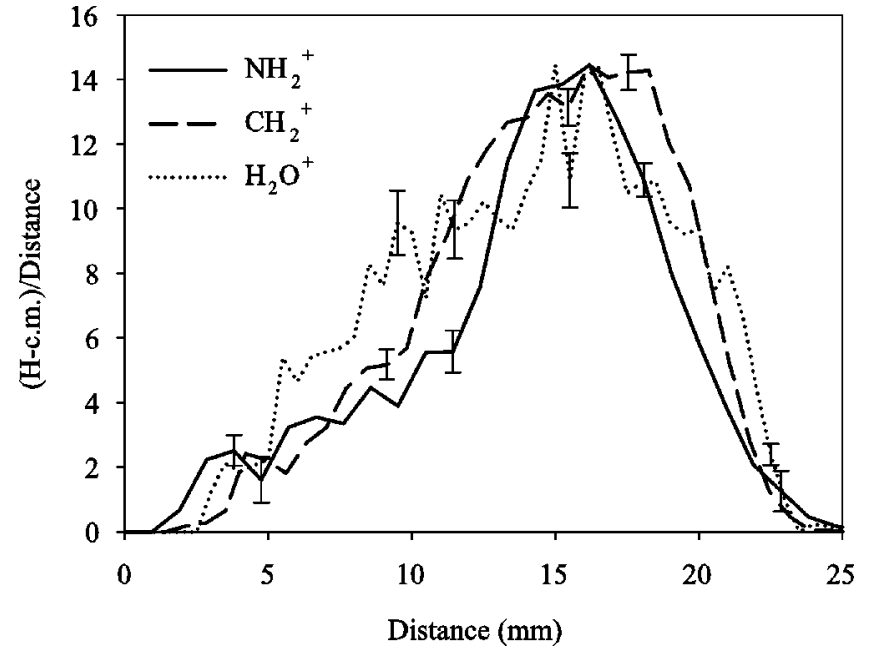

FIG. 8. Energy distribution for the two hydrogen atoms for events which preferentially dissociate parallel to the detector. Data from the current ions, $\mathrm{NH}_{2}^{+}$(solid line), and $\mathrm{CH}_{2}^{+}$(dashed line), are plotted with those data for $\mathrm{H}_{2} \mathrm{O}^{+}$(dotted line) from our earlier work [25]. Data have been scaled in both axes to facilitate comparison.

$\left(X^{2} A_{1}\right)$ of $\mathrm{CH}_{2}^{+}$has a minimum at $\approx 140 \pm 5^{\circ}\left[\cos \left(\chi_{D}\right)=\right.$ $-0.77 \pm 0.03]$. Although both these ions are bent, the barrier to linear geometry is small in both cases, 0.12 and $0.03 \mathrm{eV}$ for $\mathrm{CH}_{2}^{+}$and $\mathrm{NH}_{2}^{+}$, respectively. This compares to almost 1 $\mathrm{eV}$ in the case of $\mathrm{H}_{2} \mathrm{O}^{+}$. The present data for $\mathrm{CH}_{2}^{+}$suggest a preferred open geometry on dissociation, indicating that there is little change in structure in moving from the ion to the neutral after capturing the electron. In the case of $\mathrm{NH}_{2}^{+}$ the feature at highly bent geometries suggests that there are instances in which the structure does change, though the data at more open angles suggest that there are also dissociating states which have a similar geometry to that of the ionic ground state. Similar observations to those obtained for $\mathrm{NH}_{2}^{+}$ were also observed for $\mathrm{H}_{2} \mathrm{O}^{+}$[25], where subsequent investigation showed the possible involvement of bent and superbent electronically excited neutral states in the DR process [25]. Analogous states might similarly play a role in the DR of $\mathrm{NH}_{2}^{+}$.

\section{Energy distribution}

It is also possible to study the kinetic energy sharing between the two hydrogen atoms from the imaging data [25]. As with the investigation of the intermolecular angle only those events which have the greatest TD were used, and analyzed according to Eq. (6). As noted in our earlier paper, these data are difficult to interpret in themselves, and only when combined with the Monte Carlo simulations can meaningful conclusions be drawn [25]. However, comparison between $\mathrm{CH}_{2}^{+}, \mathrm{NH}_{2}^{+}$, and the previously reported $\mathrm{H}_{2} \mathrm{O}^{+}$data [25] is enlightening. Figure 8 plots all these data. It is noted that the data have been scaled, in both axes, to facilitate comparison. There are some similarities and differences among the distributions. For $\mathrm{NH}_{2}^{+}$(solid line), the distribution is more clearly peaked than for $\mathrm{CH}_{2}^{+}$(dashed line) and $\mathrm{H}_{2} \mathrm{O}^{+}$(dotted line). Furthermore, though the distribution ob- tained for $\mathrm{CH}_{2}^{+}$is similar to that of $\mathrm{H}_{2} \mathrm{O}^{+}$, it is not as broad. Clearly, the available reaction energy is distributed differently in each case. As in the earlier figures, the selected error bars given in the figure are entirely statistical.

\section{MONTE CARLO SIMULATION}

To obtain some quantitative understanding of these important reaction parameters, a Monte Carlo simulation was employed. A description and discussion of the simulation can be found in Ref. [25]. Since the publication of this method, additional experimental effects have been included in the simulation. Two sources of additional reaction energy available to the fragments, arising from the rotational energy of the parent molecule as well as the higher energy collisions in the toroidal regions of the electron cooler, have now been considered. The effects were included in a recent imagingbased study on the DR of $\mathrm{NO}^{+}$where they played a significant role in understanding the experimental observations [43].

\section{A. Rotational energy}

Whilst there is sufficient evidence to conclude that a few seconds storage is sufficient to allow vibrationally excited molecular ions with a permanent dipole moment to decay to their vibrational ground state, the same cannot be said for rotationally excited molecules. Such conclusions were based on DR studies of $\mathrm{H}_{3}^{+}[2,44]$. In the experiments presented here it is assumed that the rotational temperature $T_{\text {rot }}$ is described by the filament temperature in the ion source, i.e., $T_{\text {rot }} \approx 1000 \mathrm{~K}$. Including the effects of the rotational temperature is not as straightforward as for diatomic molecules. However, since our interest is in the general effect, several simplifying assumptions have been made which will not mirror reality but which will make calculation easier.

For $\mathrm{NH}_{2}^{+}$, the low-lying barrier $\approx 200 \mathrm{~cm}^{-1}(=0.025 \mathrm{eV})$ to linearity means that at $T_{\text {rot }} \approx 1000 \mathrm{~K}$ there is sufficient rotational energy for the majority of the molecules to be linear. A rotational constant of $8.022966 \mathrm{~cm}^{-1}$ has been reported for linear $\mathrm{NH}_{2}^{+}$[45].

For $\mathrm{CH}_{2}^{+}$, the energy required to linearity $(0.12 \mathrm{eV})$ is larger than could be expected from the rotational distribution in the source. The complexity involved in accurately determining the energy stored in the rotational levels of a nonlinear asymmetric top molecule is beyond the model's simple requirement. However, a simplified and accepted approach [46] treats the energy in each rotational level as the same as that of a linear molecule with an average of the three individual rotational constants. Using data given in Graber et al. [41], the three rotational constants are found to be 67.8649, 8.0624 , and $7.2063 \mathrm{~cm}^{-1}$, respectively, giving a value of $27.7112 \mathrm{~cm}^{-1}$ which is used in the calculation.

\section{B. Toroidal sections}

In addition to the $85 \mathrm{~cm}$ length of the electron cooler where the velocity vector of the ions and electrons are parallel, there are two short sections where the electrons are bent in to and out from the cooler. As the angle between the 
two beams increases, the relative collision energy also increases. This so-called "toroidal effect," though well characterized and considered in all measurements of DR cross sections (see Ref. [47] for a thorough discussion), was only recently included in the analysis of imaging data in studying the DR of $\mathrm{NO}^{+}$[43]. The same approach was used in the simulations carried out here, with one notable difference. For both $\mathrm{CH}_{2}^{+}$and $\mathrm{NH}_{2}^{+}$branching data at nonzero collision energies are not available. An equal branching between the available channels was considered and the sensitivity of this assumption was tested by using different values. The magnitude of the contribution in each part of the toroidal region depends on the DR cross section, and the data reported by Vikor et al. [30] for $\mathrm{NH}_{2}^{+}$and by Larson et al. [29] for $\mathrm{CH}_{2}^{+}$ were used in the calculation.

\section{MONTE CARLO SIMULATION RESULTS}

The results obtained from the Monte Carlo simulations are presented here and, to simplify the discussion, the main experimental parameters are considered separately.

\section{A. Branching ratio}

To obtain the electronic branching the simulation was run for each of the available kinetic energies of the possible branches and states. The obtained TD distributions were then independently scaled until the sum of these data sets best matched the experimentally measured distributions. The branching ratio between the populated channels was then given by the ratio of these scaling factors.

It was initially assumed from the $\mathrm{NH}_{2}^{+}$data that the reaction channel producing $\mathrm{N}\left({ }^{2} P\right)$ was not populated, and the simulation allows us to investigate this in more detail. Figure 9 plots the experimentally determined TD data $(\mathbf{O})$ together with the simulation. TD data for the three available channels, $\mathrm{N}\left({ }^{2} P\right)$ (dot-dashed line), $\mathrm{N}\left({ }^{2} D\right)$ (dotted line), and $\mathrm{N}\left({ }^{4} S\right)$ (dashed line) are plotted with the sum of these scaled distributions (solid line). The inset in Fig. 9 shows an expanded view of data at low values of TD. Since there is no obvious peak corresponding to the channel leading to $\mathrm{N}\left({ }^{2} P\right)$, the amplitude of this channel has been scaled such that the summed TD curve best fits the experimental data.

The effect of the foil has been included in this simulation. The foil actively discriminates against fragments with a low transverse kinetic energy, since the hydrogen atoms strike the foil and are stopped. From the simulation, $4 \%$ of $\mathrm{N}\left({ }^{4} S\right), 9 \%$ of $\left.\mathrm{N}^{2} D\right)$, and $45 \%$ of $\left.\mathrm{N}^{2} P\right)$ events are lost due to the foil, respectively. Including other sources of uncertainty, i.e., mostly due to the fitting procedure, the final percentage fractions for $\mathrm{N}\left({ }^{4} S\right): \mathrm{N}\left({ }^{2} D\right): \mathrm{N}\left({ }^{2} P\right)$ are $0.53(4): 0.45(5): 0.02(2)$.

From the fit, only $2 \%$ of DR events produce $\mathrm{N}\left({ }^{2} P\right)$. The low kinetic energy release coupled with the foil complicates detection of this channel. The simulation indicates that a significant population of this channel, i.e., $\approx 10 \%$, would almost certainly have been observed in the TD distribution. It is concluded that the majority of DR events lead to the production of $\mathrm{N}\left({ }^{4} S\right)$ and $\mathrm{N}\left({ }^{2} D\right)$, with almost equal probability, and though the production of $\left.\mathrm{N}^{2} \mathrm{P}\right)$ cannot be completely ruled

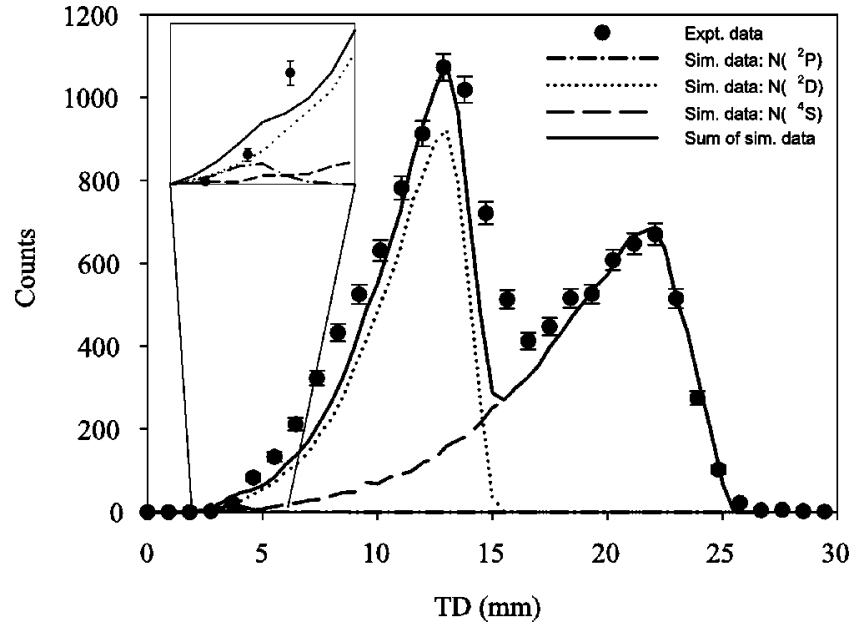

FIG. 9. The experimentally determined TD $(\bullet)$ of all the threebody fragments from the $\mathrm{DR}$ of $\mathrm{NH}_{2}^{+}$. Also plotted are the individual TD calculated by the Monte Carlo simulation for the three available channels, $\mathrm{N}\left({ }^{2} P\right)$ (dot-dash line), $\mathrm{N}\left({ }^{2} D\right)$ (dotted line) and $\mathrm{N}\left({ }^{4} S\right)$ (dashed line). The individual distributions have been independently scaled such that their total (solid line) gives the best approximation to the experimentally measured data. The inset shows an expanded view of data at low values of TD.

out it is unfavored. The fit to the data is not perfect, and it is possible that there are effects in the case of $\mathrm{NH}_{2}^{+}$which have not been sufficiently considered in the simulation, e.g., we have overestimated the resolution. However, it is noted that the data obtained from both $\mathrm{CH}_{2}^{+}$and $\mathrm{H}_{2} \mathrm{O}^{+}$[25] are fit much better.

For $\mathrm{CH}_{2}^{+}$the situation is more straightforward. Figure 10 plots the experimentally determined TD data $(\bullet)$ together with the results from the simulation. TD data calculated for $\mathrm{C}\left({ }^{1} D\right)$ (dotted line) and $\mathrm{C}\left({ }^{3} P\right)$ (dashed line) are plotted to-

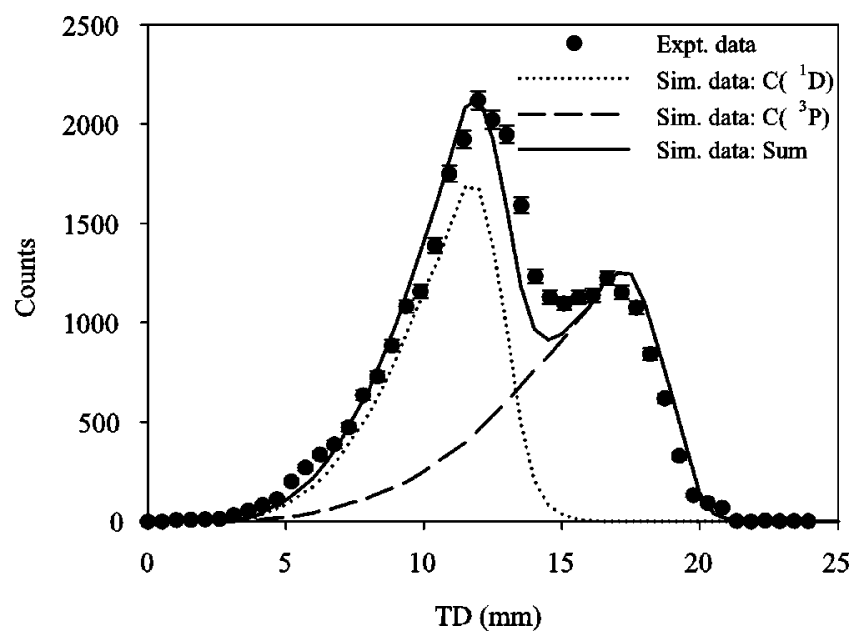

FIG. 10. The experimentally determined TD $(\mathbf{)})$ of the threebody fragments from the $\mathrm{DR}$ of $\mathrm{CH}_{2}^{+}$, together with the distributions calculated by the Monte Carlo simulation for the two available channels leading to the production of $\mathrm{C}\left({ }^{1} D\right)$ (dashed line) and $\mathrm{C}\left({ }^{3} P\right)$ (dotted line). These distributions have been independently scaled such that their total (solid line) gives the best approximation to the experimentally measured data. 


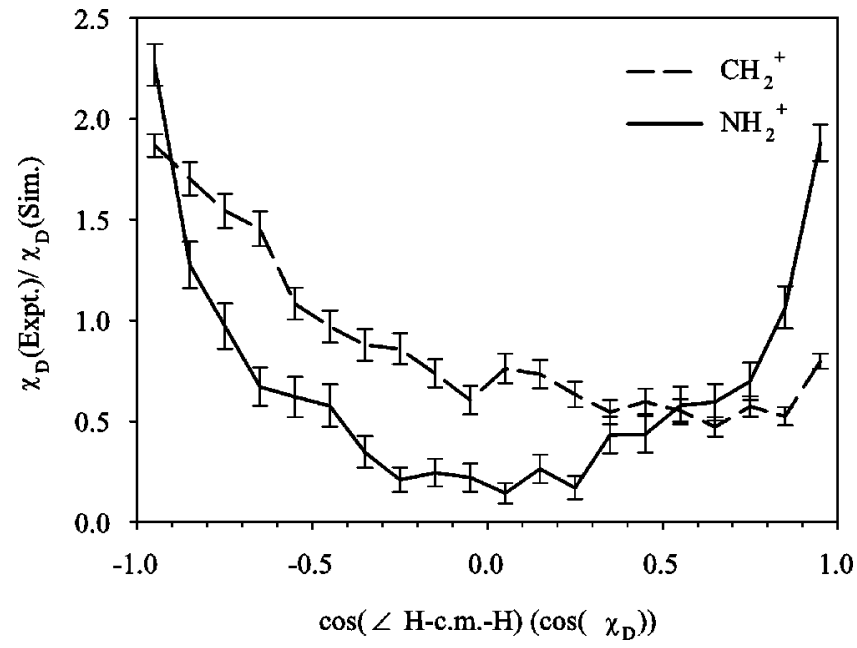

FIG. 11. The ratio of the $\chi_{D}$ distribution observed in the experiment (Fig. 7) to that obtained from the simulation where the H-c.m.-H angle is unconstrained. Such data are plotted for both $\mathrm{CH}_{2}^{+}$(dashed line) and $\mathrm{NH}_{2}^{+}$(solid line).

gether with the sum of these distributions (solid line) scaled to yield the best approximation to the experimentally measured data. $5 \%$ of $\mathrm{C}\left({ }^{3} P\right)$, and $10 \%$ of $\mathrm{C}\left({ }^{1} D\right)$ events are lost due to the foil. Using the obtained fitted scaling factors gives a final branching fraction to the channels, $\mathrm{C}\left({ }^{3} P\right): \mathrm{C}\left({ }^{1} D\right)$, of $0.51(4): 0.49(5)$.

\section{B. Angular distribution}

In our previous paper on $\mathrm{H}_{2} \mathrm{O}^{+}$a good interpretation of the geometry of the dissociating states was obtained by comparing the measured angular distribution $\chi_{D}$ with that predicted from a purely random initial distribution $\chi_{i}$ in the molecular frame (see Fig. 11 in Ref. [25]). Figure 11 plots the comparison data obtained for $\mathrm{CH}_{2}^{+}$(dashed line) and $\mathrm{NH}_{2}^{+}$ (solid line).

To investigate the fragmentation of $\mathrm{H}_{2} \mathrm{O}^{+}$an initial distribution $\chi_{i}$ was created via trial and error for which the simulated and experimental $\chi_{D}$ were in acceptable agreement. The ratio of these distributions compared well with the ratio of the trial and isotropic $\chi_{i}$ distributions (see the bottom panel of Fig. 12 in Ref. [25]).

Since this approach worked well, an initial $\chi_{i}$ distribution was obtained from the isotropic distribution and the experimental/isotropic $\chi_{D}$ ratio. Figure 12 plots the isotropic (dotted line) $\chi_{i}$ distribution, together with the calculated $\mathrm{CH}_{2}^{+}$ (dashed line) and $\mathrm{NH}_{2}^{+}$(solid line) $\chi_{i}$ distributions. The earlier conclusions are borne out. The initial $\mathrm{NH}_{2}$ angular distribution shows a preference (higher than expected from a random distribution) for bent and linear geometries, whilst that of $\mathrm{CH}_{2}$ shows a preference for open geometries.

\section{H atom energy distribution}

In the simulation the distribution of energy is parametrized by $\rho\left(=v_{\mathrm{H}_{2}}^{2} / v_{\mathrm{H}_{1}}^{2}\right)$. As in our earlier study, three expressions for $\rho$ were used to investigate our observations, $\rho$

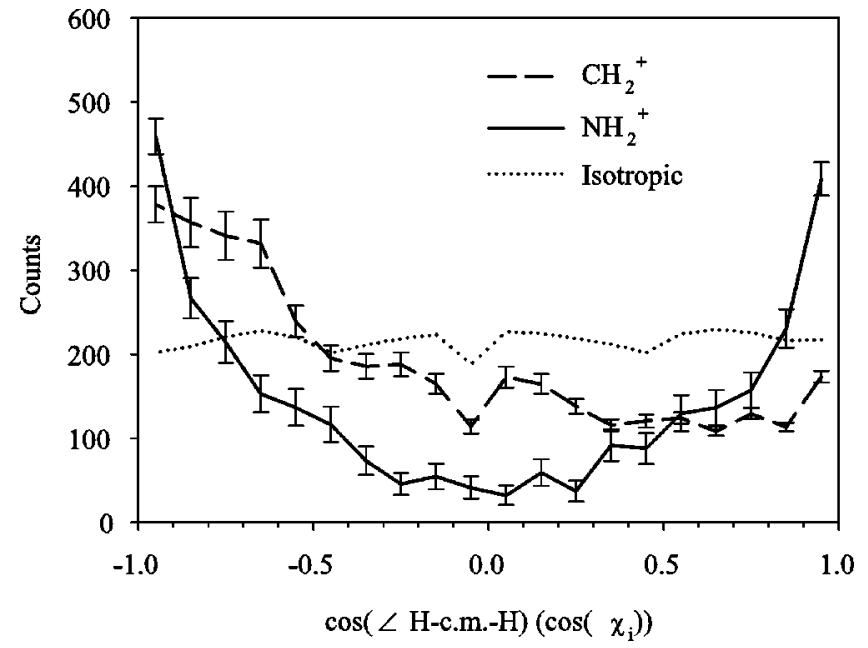

FIG. 12. Suggested initial $\chi_{i}$ angular distributions for $\mathrm{CH}_{2}^{+}$ (dashed line) and $\mathrm{NH}_{2}^{+}$(solid line) obtained from the isotropic distribution (dotted line) and the $\chi_{D}$ ratios given in Fig. 11.

$=1, \rho=0.1$, and $\rho=r$, respectively [25]. The first of these cases describes equal energy sharing. The second is where one atom gets $90 \%$ of the available energy. The last case represents a flat distribution of values between 0 and 1 . Results for each of these cases are plotted in Fig. 13. Experimental data (-) for $\mathrm{NH}_{2}^{+}$and $\mathrm{CH}_{2}^{+}$are displayed in the top and bottom panel, respectively, together with the results for $\rho=1$ (solid line), $\rho=0.1$ (dashed line), and $\rho=r$ (dotted line).

None of these cases proves a perfect fit to the experimental data. However, the results do provide some interesting insights. The case $\rho=0.1$ is by far the worst description of both the $\mathrm{CH}_{2}^{+}$and $\mathrm{NH}_{2}^{+}$experimental data. The significant maxima in the $\mathrm{NH}_{2}^{+}$data are well described by $\rho=1$, rather than the case where $\rho=r$, though some broadening is necessary to completely describe the data. The case of $\rho=1$ would be highly indicative of a strictly simultaneous breakup, where both the H-N bonds are synchronously stretched to the point of dissociation. Though the peak is a good match, the broadening, together with the large wings, indicates that the dissociation might not be strictly simultaneous. Since the peak in the distribution is so well defined, it is interesting to investigate what function of $\rho$ is mainly responsible for it. The top panel (a) in Fig. 14 displays the experimental data for $\mathrm{NH}_{2}^{+}\left(-\mathrm{O}_{-}\right)$together with the results obtained from the simulation for the case where $\rho=0.4+r \times 0.6$ and the inset graph in this panel plots the distribution of $\rho$. This function of $\rho$ predicts the maximum difference in the energy between the hydrogen atoms is 2.5 , i.e., $v_{\mathrm{H}_{2}}^{2} / v_{\mathrm{H}_{1}}^{2}=0.4, v_{\mathrm{H}_{1}}^{2}=2.5 v_{\mathrm{H}_{2}}^{2}$.

From the $\mathrm{CH}_{2}^{+}$data, the distribution is very much broader than the case when $\rho=1$, and is more similar to the case where $\rho=r$. This is similar to that of $\mathrm{H}_{2} \mathrm{O}^{+}$. Thus it is even more clear for $\mathrm{CH}_{2}^{+}$than it was for $\mathrm{NH}_{2}^{+}$that fragmentation does not proceed via a strictly simultaneous mechanism and that the dissociation is best described by an asynchronous concerted mechanism. As implemented for $\mathrm{NH}_{2}^{+}$, the function of $\rho$ which best described the experimental data was investigated. The bottom panel (b) in Fig. 14 displays both the experimental data for $\mathrm{CH}_{2}^{+}$(-) - together with the results obtained from the simulation for the case where $\rho=0.2+r$ 


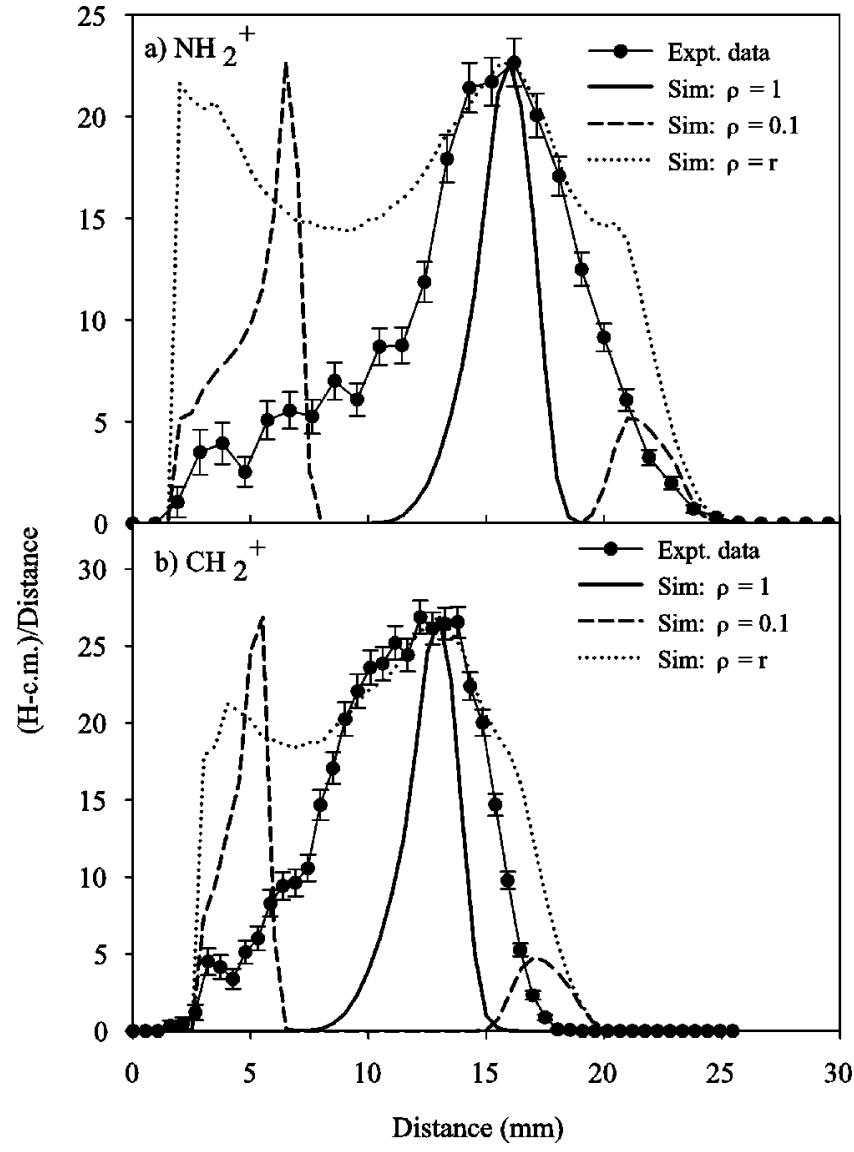

FIG. 13. Energy distributions for the two hydrogen atoms for events which preferentially dissociate parallel to the detector. Experimental data for $\mathrm{NH}_{2}^{+}$are given in the upper panel (a) and for $\mathrm{CH}_{2}^{+}$in the lower panel (b). Experimental data for each case (-0-) are plotted and compared with three different simulated cases for the $\rho$ parameter, $\rho$ being the ratio of the $\mathrm{H}$ atom energies. The three cases are $\rho=1.0$ (solid line), $\rho=0.1$ (dashed line), and $\rho=r$ (dotted line). The first case corresponds to the situation where the energy is always equally shared. The second case is where one atom always gets $90 \%$. The last case represents a flat distribution of values between 0 and 1 .

$\times 0.8$, with the inset graph showing the distribution of $\rho$ obtained. The maximum difference in the energy between the hydrogen atoms is 5, i.e., $v_{\mathrm{H}_{2}}^{2} / v_{\mathrm{H}_{1}}^{2}=0.2, v_{\mathrm{H}_{1}}^{2}=5 v_{\mathrm{H}_{2}}^{2}$.

No comprehensive interpretation of the observed behavior can be made. However, it is worth noting that for the triatomic systems studied so far, as the ion ground state moves away from a linear geometry the product $\mathrm{H}$ atom energy distribution becomes more random $(\rho=r)$. We have no mechanistic explanation for this observation.

\section{DISCUSSION}

To provide a clear basis for discussion, Table II collects together all of the results obtained from our DR studies of $\mathrm{CH}_{2}^{+}, \mathrm{NH}_{2}^{+}$, and $\mathrm{OH}_{2}^{+}$. For each ion, the initial state data are listed, i.e., the ionization energy (IE) the minimum angle geometry $\Theta_{e}$, and the character of the state. The results for the chemical branching, following DR with zero-eV elec-

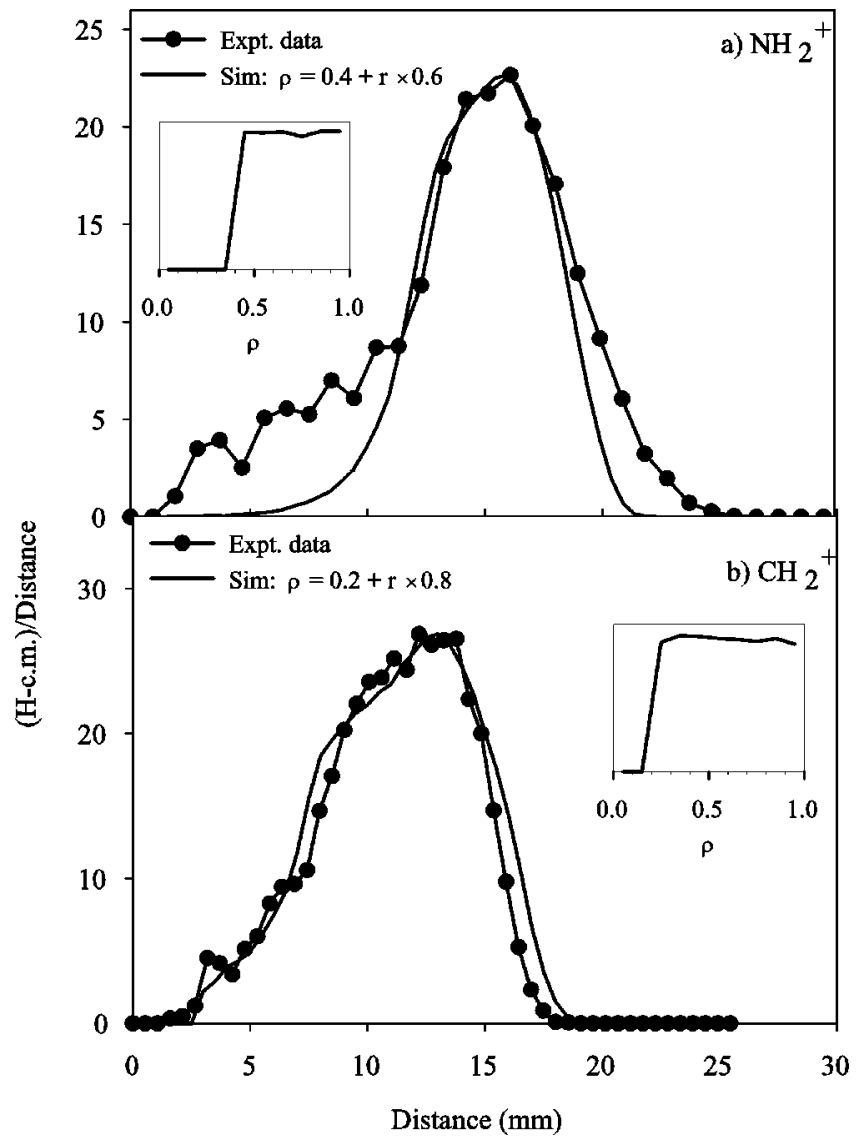

FIG. 14. Energy distributions for the two hydrogen atoms for events which preferentially dissociate parallel to the detector. Experimental data (-) for $\mathrm{NH}_{2}^{+}$and for $\mathrm{CH}_{2}^{+}$are given in the upper (a) and lower (b) panels, respectively. These data are plotted and compared with a "best fit" simulation for the $\rho$ parameter (solid line), $\rho=0.4+r \times 0.6$ and $\rho=0.2+r \times 0.8$ for $\mathrm{NH}_{2}^{+}$and $\mathrm{CH}_{2}^{+}$, respectively, and where $r$ is a random number from a flat distribution of values between 0 and 1 . The inset graph in each panel plots the distribution of $\rho$ used in that particular simulation.

trons, are given in columns 3-5, with the data for $\mathrm{CH}_{2}^{+}$[29], $\mathrm{NH}_{2}^{+}$(present data), and $\mathrm{OH}_{2}^{+}$[31], respectively. Columns 6-10 detail the information obtained from the investigations into the three-body fragmentation channels, with data for $\mathrm{CH}_{2}^{+}$and $\mathrm{NH}_{2}^{+}$reported here and for $\mathrm{H}_{2} \mathrm{O}^{+}$from Ref. [25]. The branching fractions given in column 8 have been predicted from two models, the first described in Ref. [25] and, in brackets, from that used in Ref. [43]. The data for $\mathrm{NH}_{2}^{+}$ and $\mathrm{CH}_{2}^{+}$are plotted in columns 9 and 10 , and for $\mathrm{H}_{2} \mathrm{O}^{+}$as reported in Ref. [25].

Two simple methods have been recently used to predict the branching in DR. One was developed to model the DR of diatomic molecules [48] and used in the recent investigation into the $\mathrm{DR}$ of $\mathrm{NO}^{+}[43]$. The second was used to study the three-body fragmentation of $\mathrm{H}_{2} \mathrm{O}^{+}$[25]. Both models involve considering the electronic degeneracy of the reaction products, with the latter model also considering the available kinetic energy to account for the translational degrees of freedom, and both represent purely statistical approaches to the DR reaction, and absolutely do not consider any underlying dynamical processes. 
TABLE II. Table of DR results for $\mathrm{CH}_{2}^{+}, \mathrm{NH}_{2}^{+}$, and $\mathrm{H}_{2} \mathrm{O}^{+}$. For each ion, column 2 lists the initial state data, i.e., the ionization energy IE, the minimum angle geometry $\Theta_{e}$, and the character of the state. Columns 3 and 4, respectively, list the available fragmentation channels with their kinetic energies assuming ground-state fragments, following DR with 0-eV electrons. Column 5 gives the results for the DR reaction as measured at CRYRING. Columns 6-10 list those data associated with the investigations into the competition between the available three-body fragmentation channels. Column 6 lists the available channels, giving the excitation state of the heavy atom as well as the kinetic energy associated with that channel. Column 7 lists the obtained experimental branching results while column 8 shows the predictions obtained from models used in Ref. [25] and in (Ref. [43]). Finally, columns 9 and 10 show a graphical representation of the angular distribution and kinetic-energy distribution between the $\mathrm{H}$-atom fragments, respectively, for selected reactions leading to the production of the ground-state heavy fragments only. For the plots in column 9, open linear geometry is to the left and small-angle geometry to the right.

\begin{tabular}{|c|c|c|c|c|c|c|c|c|c|}
\hline \multirow{4}{*}{ Ion } & \multirow{4}{*}{$\begin{array}{c}\text { Initial } \\
\text { state data }\end{array}$} & \multicolumn{3}{|c|}{ Chemical Branching } & \multicolumn{5}{|c|}{ Three-body Competition } \\
\hline & & \multirow{3}{*}{$\begin{array}{l}\text { Neutral } \\
\text { Channels }\end{array}$} & \multirow{3}{*}{$\begin{array}{c}\text { Ground } \\
\text { state } \\
\text { Energies }\end{array}$} & \multirow{3}{*}{$\begin{array}{l}\text { Branching } \\
\text { fraction }\end{array}$} & \multirow{3}{*}{$\begin{array}{l}\text { Three-body } \\
\text { Channels }\end{array}$} & \multirow{2}{*}{\multicolumn{2}{|c|}{$\begin{array}{l}\text { Branching } \\
\text { fraction }\end{array}$}} & \multicolumn{2}{|c|}{ Ground state } \\
\hline & & & & & & & & Angular & H-Energy \\
\hline & & & & & & Expt. & Models $^{g}$ & Distribution & Distribution \\
\hline \multirow[t]{4}{*}{$\mathrm{CH}_{2}^{+}$} & \multirow{2}{*}{$\begin{array}{c}\operatorname{IE}\left(\mathrm{CH}_{2}\right): 10.396 \mathrm{eV}^{a} \\
\Theta_{e}: \approx 138^{\circ b}\end{array}$} & $\mathrm{C}+\mathrm{H}_{2}$ & $6.80 \mathrm{eV}$ & $0.12^{d}$ & \multirow[b]{2}{*}{$\mathrm{C}\left({ }^{3} \mathrm{P}\right), 2.45 \mathrm{eV}$} & \multirow[b]{2}{*}{$0.51^{e}$} & \multirow[b]{2}{*}{$0.72(0.64)$} & \multirow[t]{4}{*}{ e } & \multirow[t]{4}{*}{ e } \\
\hline & & $\mathrm{CH}+\mathrm{H}$ & $5.80 \mathrm{eV}$ & 0.25 & & & & & \\
\hline & State: ${ }^{2} A_{1}$ & $\mathrm{C}+\mathrm{H}+\mathrm{H}$ & $2.45 \mathrm{eV}$ & 0.63 & & & & & \\
\hline & Radical species & & & & $\mathrm{C}\left({ }^{1} \mathrm{D}\right), 1.19 \mathrm{eV}$ & 0.49 & $0.28(0.36)$ & & \\
\hline \multirow[t]{5}{*}{$\mathrm{NH}_{2}^{+}$} & \multirow{5}{*}{$\mid \begin{array}{c}\mathrm{IE}\left(\mathrm{NH}_{2}\right): 11.163 \mathrm{eV}^{c} \\
\Theta_{e}: \approx 150^{\circ b} \\
\text { State: }{ }^{3} \mathrm{~B}_{1} \\
\text { Closed shell species }\end{array}$} & $\mathrm{N}+\mathrm{H}_{2}$ & $8.24 \mathrm{eV}$ & $0.04^{e}$ & \multirow[b]{2}{*}{$\mathrm{N}\left({ }^{4} \mathrm{~S}\right), 3.72 \mathrm{eV}$} & \multirow[b]{2}{*}{$0.53^{e}$} & \multirow[b]{2}{*}{$0.36(0.20)$} & \multirow[t]{5}{*}{ e } & \multirow[t]{5}{*}{$e$} \\
\hline & & $\mathrm{NH}+\mathrm{H}$ & $6.97 \mathrm{eV}$ & 0.39 & & & & & \\
\hline & & $\mathrm{N}+\mathrm{H}+\mathrm{H}$ & $3.72 \mathrm{eV}$ & 0.57 & $\mathrm{~N}\left({ }^{2} \mathrm{D}\right), 1.34 \mathrm{eV}$ & 0.45 & $0.54(0.50)$ & & \\
\hline & & & & & & & & & \\
\hline & & & & & $\mathrm{N}\left({ }^{2} \mathrm{P}\right), 0.14 \mathrm{eV}$ & 0.02 & $0.10(0.30)$ & & \\
\hline \multirow[t]{4}{*}{$\mathrm{OH}_{2}^{+}$} & \multirow{3}{*}{$\begin{array}{c}\operatorname{IE}\left(\mathrm{H}_{2} \mathrm{O}\right): 12.296 \mathrm{eV}^{c} \\
\Theta_{e}: \approx 108^{\circ b} \\
\text { State: }{ }^{2} \mathrm{~B}_{1}\end{array}$} & $\mathrm{O}+\mathrm{H}_{2}$ & $6.97 \mathrm{eV}$ & $0.09^{f}$ & \multirow{3}{*}{$\mathrm{O}\left({ }^{3} \mathrm{P}\right), 3.04 \mathrm{eV}$} & \multirow{3}{*}{$0.78^{h}$} & \multirow{3}{*}{$0.75(0.64)$} & \multirow{3}{*}{$h$} & \\
\hline & & $\mathrm{OH}+\mathrm{H}$ & $6.96 \mathrm{eV}$ & 0.20 & & & & & \\
\hline & & $\mathrm{O}+\mathrm{H}+\mathrm{H}$ & $3.04 \mathrm{eV}$ & 0.71 & & & & & \\
\hline & Open shell species & & & & $\mathrm{O}\left({ }^{1} \mathrm{D}\right), 1.07 \mathrm{eV}$ & 0.22 & $0.25(0.36)$ & & \\
\hline
\end{tabular}

${ }^{a}$ Data taken from the NIST webbook [36].

${ }^{\mathrm{b}}$ Values for $\Theta_{e}$ taken from the data reported in Table I of Graber et al. [41].

${ }^{c}$ Data for IE $\left(\mathrm{NH}_{2}\right)$ taken from Dyke [35].

${ }^{\mathrm{d}}$ Branching data from the DR of $\mathrm{CH}_{2}^{+}$taken from Larson et al. [29].

${ }^{\mathrm{e}}$ Data reported here.

${ }^{\mathrm{f}}$ Branching data from the DR of $\mathrm{H}_{2} \mathrm{O}^{+}$taken from Rosén et al. [31].

${ }^{\mathrm{g}}$ Values obtained from models used in our earlier work [25] and, in brackets, from Hellberg et al. [43].

${ }^{h}$ Data reported in our earlier work on $\mathrm{H}_{2} \mathrm{O}^{+}[25]$.

The results from these models generally compare well with experimental observations, for the diatomic $[43,48]$ and three-body DR processes [25], and the data presented here represent another test of these models, especially the latter. In both models the degeneracies due to the product hydrogen atoms were ignored as they occur in all channels.

For $\mathrm{NH}_{2}$, the degeneracies of the three possible excitation states of nitrogen, $\mathrm{N}\left({ }^{4} S\right), \mathrm{N}\left({ }^{2} D\right)$, and $\mathrm{N}\left({ }^{2} P\right)$, are 4,10 , and 6 , respectively. The $\mathrm{N}\left({ }^{4} S\right): \mathrm{N}\left({ }^{2} D\right): \mathrm{N}\left({ }^{2} P\right)$ branching fractions predicted by the diatomic and three-body models are 0.20:0.50:0.30, and 0.36:0.54:0.10, respectively. Both methods predict $\mathrm{N}\left({ }^{2} D\right)$ to be the dominant product at $\approx 50 \%$. However, they differ regarding the second-most dominant channel. The diatomic model predicts $\mathrm{N}\left({ }^{2} P\right)$ to be more favored than $\mathrm{N}\left({ }^{4} S\right)$ while the three-body model predicts the opposite. While there is a disagreement, both clearly predict 


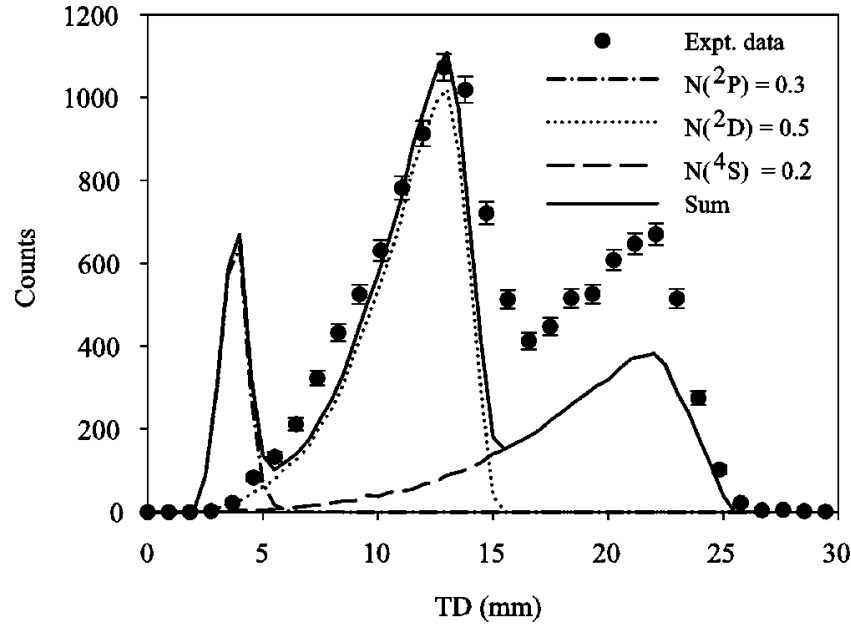

FIG. 15. Data plotted as for Fig. 9 using the branching ratios predicted using the model suggested by Hellberg et al. [43].

a significant production of $\left.\mathrm{N}^{2} P\right)$. Using the prediction from the diatomic model of a 0.30 branching to $\left.\mathrm{N}^{2} P\right)$, results from the Monte Carlo simulation indicate the channel should be clearly visible in the TD distribution data. This is illustrated in Fig. 15.

For $\mathrm{CH}_{2}$, the degeneracy of the two possible excitation states of carbon, $C\left({ }^{3} P\right)$ and $C\left({ }^{1} D\right)$, are 9 and 5 , respectively. These values are identical to those of the $\mathrm{O}\left({ }^{3} P\right)$ and $\mathrm{O}\left({ }^{1} D\right)$ products in the DR of $\mathrm{H}_{2} \mathrm{O}^{+}$and, with similar kinetic energies, the three-body model predicts the similar result that the production of $\mathrm{C}\left({ }^{3} P\right)$ is preferred by a factor of 3 . The diatomic model predicts the same result. This is in clear disagreement with the experimental observation that both channels are almost equally populated.

Thus both models fail to predict the experimentally observed branching fractions with the same success as for $\mathrm{H}_{2} \mathrm{O}^{+}$. For $\mathrm{H}_{2} \mathrm{O}^{+}$it was still concluded from the degree of dynamics observed to be occurring that it was unlikely that the branching would be purely statistical and agreement with the model prediction was fortuitous [25]. This is most clearly demonstrated when comparing $\mathrm{H}_{2} \mathrm{O}^{+}$and $\mathrm{CH}_{2}^{+}$. The threebody fragmentation model predicts the same branching fractions in both of these cases, and yet the measurements give vastly different branching behavior.

It is difficult to reconcile the generally good agreement of the diatomic model for diatomic DR reactions and the poor agreement of both models with respect to the three-body results reported here. The conclusion that dynamics plays a large role in the DR process, and that the reaction cannot be described by a simple statistical model, cannot then be ignored.

Consideration of the dynamics involved in the three-body fragmentation process is nontrivial. The earlier study on $\mathrm{H}_{2} \mathrm{O}^{+}$highlighted the chronic lack of available information on those states which might play a role in the process. From an experimental perspective, information on these states is usually obtained from photodissociation studies and, from a theoretical point of view, the complexity of such states makes calculation extremely complicated. For example, of the 50 states predicted for $\mathrm{H}_{2} \mathrm{O}$ only 9 have known/ calculated potential functions. Even with such limited data, trajectory calculations showed that three-body fragmentation was a natural outcome of the dynamics on those surfaces [25]. Most states produced ground state $\mathrm{O}\left({ }^{3} P\right)$ oxygen, with only the highest state leading to an appreciable amount of $\mathrm{O}\left({ }^{\mathrm{I}} D\right)$. Unfortunately, this surface is almost $3 \mathrm{eV}$ below the ionization energy of $\mathrm{H}_{2} \mathrm{O}$, and the contribution of those states within this region could not be determined. Interestingly, it is reported that photodissociation of $\mathrm{H}_{2} \mathrm{O}$ at wavelengths shorter than Lyman- $\alpha$, i.e., from surfaces closer to the ionization limit, gave higher $\mathrm{O}\left({ }^{1} D\right)$ production [49]. The calculations performed indicated a significant degree of mixing of triplet and singlet surfaces, via conical intersections, and also of importance, that these surfaces showed a large range in geometries, e.g., from a superbent $15^{\circ}$ to a linear $180^{\circ}$ [25]. All of these observations and calculations supported the experimental observations in $\mathrm{DR}$ of $\mathrm{H}_{2} \mathrm{O}^{+}$.

A similar situation exists for $\mathrm{NH}_{2}$ and $\mathrm{CH}_{2}$. There are few data available for high-lying surfaces which could play a large role in the DR process, especially with respect to the three-body breakup of the molecule. More readily available information on lower-lying surfaces are available, which might provide indications of potential changes in geometry that may also be reflected in higher-lying states.

The $\mathrm{NH}_{2}$ ground state $\widetilde{X}^{2} B_{1}$ has a minimum geometry at $\approx 103^{\circ}[12,50-53]$, and the minimum geometry of the first $\widetilde{A}^{2} A_{1}\left(\approx 1.38 \mathrm{eV}\right.$ above $\left.\widetilde{X}^{2} B_{1}\right)$ and second $\widetilde{B}^{2} B_{2}(\approx 4.34 \mathrm{eV}$ above $\tilde{X}^{2} B_{1}$ ) excited states are reported to be at $\approx 145^{\circ}$ [51-53], and $\approx 95^{\circ}[50,52]$, respectively.

In addition, Biehl et al., from vacuum ultraviolet (vuv) studies, report the geometry for two much higher-lying states, namely $2^{2} A_{1}\left(A^{\prime}\right) \quad\left(\approx 7.8 \mathrm{eV}\right.$ above $\left.\tilde{X}^{2} B_{1}\right)$ and $1^{2} A_{2} / 3^{2} B_{1}\left(\approx 9.4 \mathrm{eV}\right.$ above $\left.\tilde{X}^{2} B_{1}\right)$, to be $\approx 103^{\circ}$ and $\approx 180^{\circ}$, respectively [12]. Furthermore, geometries of the lowestlying electronic states of $\mathrm{NH}_{2}^{+}$may be also relevant, as Rydberg states that converge to these ions may also be accessible in the current experiment. For the two lowest excited states, $\widetilde{a}^{1} A_{1}$ and $\widetilde{b}^{1} B_{1}$, Stephens et al. [51] report geometries that have minima at $\approx 108^{\circ}$ and $\approx 180^{\circ}$, respectively.

There is a broad range in the geometry of the excited states in $\mathrm{NH}_{2}$, certainly in the higher-lying Rydberg levels converging to the excited ionic states. If, on attaching an electron, the ion moves from the linear ground $\left(X^{2} A_{1}\right)$ state to any of the states having bent or superbent geometry, this must involve a high degree in change in torque of the molecule, coupled with a large change in the bending potentials of the molecular system. Furthermore, moving to dissociative surfaces with the same geometry as the ground state would involve no such radical changes.

Conical intersections allow the system to move between such different surfaces. The effect of these was calculated and used to describe the observations by Dixon et al. in their photodissociation study of $\mathrm{H}_{2} \mathrm{O}$ [33] and also in our interpretation of the DR study of $\mathrm{H}_{2} \mathrm{O}^{+}$[25]. From detailed calculations, Brandi et al. [50] report two low-lying conical intersections which they conclude are of importance to the photodissociation dynamics of $\mathrm{NH}_{2}$. One such intersection, between the $\widetilde{A}^{2} A_{1}$ and $\widetilde{B}^{2} B_{2}$ states, occurs at $R \approx 2.08 \AA, \theta$ 
$\approx 68^{\circ}$, and about $4.76 \mathrm{eV}$ above the ground $\tilde{X}^{2} B_{1}$ state minimum. The second intersection, between the $1^{2} \Pi$ and $1^{2} \Sigma^{-}$ states, occurs at $\mathrm{CH}$ bond lengths of $\approx 1.027 \AA$ and $\approx 1.65 \AA$ and is about $5.11 \mathrm{eV}$ above the ground $\tilde{X}^{2} B_{1}$ state minimum.

The experimental observation that the $\mathrm{NH}_{2}$ molecule has a preference to dissociate from a combination of both open and bent geometries indicates that there are several states involved in the reaction process, and that the dynamics involved are significant.

Many impressive calculations, one-dimensional (1D), 2D, and $3 \mathrm{D}$, have been reported by the group of van Hemert [54-60] in investigating the photodissociation of $\mathrm{CH}_{2}$. Special consideration is given to triplet surfaces as well as the influence of coupled states/conical intersections, the latter aspect being driven by the work of Yarkony and co-workers [61-63]. Conical intersections play vital roles in such nonadiabatic processes as photodissociation of $\mathrm{CH}_{2}$, e.g.,

$$
\begin{aligned}
\mathrm{CH}_{2}\left(X^{3} B_{1}\right)+h \nu & \rightarrow \mathrm{CH}_{2}\left(2,3^{3} A^{\prime \prime}\right) \rightarrow \mathrm{CH}_{2}\left(2^{3} A^{\prime \prime}\right) \\
& \rightarrow \mathrm{CH}\left(X^{2} \Pi\right)+\mathrm{H}\left({ }^{2} S\right),
\end{aligned}
$$

as they occur in the Franck-Condon region of the ground state [63]. However, arriving at the necessary couplings is nontrivial $[60,61]$. Conical intersections and surface crossings play a large role in the dissociation dynamics, leading to a mixing of singlet and triplet products, and such data are vital if a complete understanding of the dissociation dynamics, even for small systems, is to be reached.

The main aim of the calculations on the photodissociation dynamics of $\mathrm{CH}_{2}$ have been geared to understanding the two-product photodissociation channels, $\mathrm{CH}+\mathrm{H}$ and $\mathrm{C}+\mathrm{H}_{2}$, with the asymptotes for the calculated surfaces just indicating which of the bimolecular products are bound with respect to that surface. The same level of understanding existed for the surfaces in $\mathrm{H}_{2} \mathrm{O}$, before these data were extended in an attempt to probe the experimental DR results [24] by including the possibility of three-body products. Relating these same asymptotes to the character of the three separate atoms, as well as to the bimolecular channels, the higher-lying states predominantly followed the channels leading to threeparticle fragmentation (see Table V in Ref. [25]) Even for the two lowest surfaces, complete fragmentation is still predicted, though only at a few percent. Knowledge of the three-particle asymptotes is necessary for a more complete picture of the relevant dynamics. To some extent, van Hemert and co-workers do make reference to the three-body asymptotes in their investigation of the dynamics of the high triplet $A^{\prime \prime}$ and $A^{\prime}$ states in $\mathrm{CH}_{2}$ [58]. For the second excited triplet state $2{ }^{3} A^{\prime \prime}$ they note a conical intersection, resulting from a crossing of the $1{ }^{3} A_{2}$ and $2{ }^{3} B_{1}$ states. For large values of the symmetric stretch co-ordinate the state assumes $A_{2}$ character, and increasing this co-ordinate the asymptote of $\mathrm{C}\left({ }^{3} \mathrm{P}\right)+\mathrm{H}+\mathrm{H}$ at $7.99 \mathrm{eV}$ is reached. On the higher-lying $5^{3} A^{\prime \prime}$ state they note many adiabatic surface crossings, and that the symmetric stretch motion is bound with the asymptote of $\mathrm{C}\left({ }^{1} D\right)+\mathrm{H}+\mathrm{H}$ at $9.42 \mathrm{eV}$. For high-lying $A^{\prime}$ states, they report that for large values of the symmetric stretch motion, the $4^{3} A^{\prime \prime}$ state couples to the asymptote of $\mathrm{C}\left({ }^{1} D\right)$
$+\mathrm{H}+\mathrm{H}$ at around $10 \mathrm{eV}$. These calculations show that the production of both ground and first excited state carbon atoms is possible from states which are accessible from the DR reaction.

Completely relevant calculations reported in the literature for the three-body dissociation channel are almost nonexistent. However, with the multiconfiguration self-consistent field (MCSCF) method in a complete active space (CAS) as a general basis, Minaev and Larsson using the linear response (LR) approach have calculated ten excited triplet and singlet states of $\mathrm{CH}_{2}$ to investigate the three-body dissociation channel [64]. To achieve a suitable degree of consistency in the results and interpretation of the calculations, Minaev and Larsson reproduced earlier results of van Hemert and co-workers [54] with respect to the two-body dissociation channels. Though qualitatively good agreement was reached with a simple geometry optimization, the MCSCF method severely underestimated the adiabatic ionization energy, $9.65 \mathrm{eV}$ rather than $10.4 \mathrm{eV}$. However, LR calculations on the excited methylene states gave extremely good agreement with the results of van Hemert and co-workers and so the defect in the MCSCF calculation was corrected by incorporating the LR technique and using the ${ }^{2} \Sigma_{g}^{+}$state as a reference (see Table 3 in Ref. [64]). Minaev and Larsson concluded that the $1^{2} \Sigma_{u}^{-}$state was the sole candidate state for the DR process. The potential-energy curve for this state crosses the ionic ground state close to the vibrational ground state, and is also bound to the asymptote leading to the production of $\mathrm{C}\left({ }^{3} P\right)+2 \mathrm{H}\left({ }^{2} S\right)$. They note that this channel is not accessible by optical means from the ground state, since although the electric dipole transition $X^{3} \Sigma_{g}^{-} \rightarrow 1^{3} \Sigma_{u}^{-}$is allowed by selection rules, the transition moment is close to zero. It is therefore not surprising that this channel has not been observed in high-energy, i.e., vuv, studies. They also comment that the same state correlates with the $3^{3} A_{2}$ state, known to have an equilibrium angle of $172^{\circ}$. They further concluded that most of the other triplet states have large barriers to the three-body DR process, as is also the case for the singlet states they calculated, and so these states were not studied further.

For the $3^{3} A_{2}$ state, correlation between the $D_{2 h}$ and $C_{2 v}$ point groups indicates that the state dissociates to the $\mathrm{C}\left({ }^{3} \mathrm{P}\right)+2 \mathrm{H}\left({ }^{2} S\right)$ limit at linear structure, but dissociates to the $\mathrm{C}\left({ }^{1} D\right)+2 \mathrm{H}\left({ }^{2} S\right)$ limit when the bond angle is $132^{\circ}$. Their interpretation that only this state fits the requirements of the DR process was supported by direct MCSCF calculations with a much larger complete active spaces and basis set. The importance of the ${ }^{3} A_{2}$ states to the three-body dissociation channels was also observed in other calculations [58].

In their detailed investigation of the ionic ground state Minaev and Larsson noted that one quantum of symmetric stretch would almost bring the state into resonance with the $3^{3} A_{2}$ state (see Fig. 5 in their paper). They concluded that easily excited bending vibrations would greatly assist the electron capture step, as well as enhance the three-body fragmentation process. The theoretical conclusion that this state is tied to $\mathrm{C}\left({ }^{3} P\right)$ production with a linear configuration is matched by the experimental observation that events producing $\mathrm{C}\left({ }^{3} P\right)$ predominantly dissociate from an open angle geometry. 
Finally, comment is made regarding the observed distribution of available kinetic energy. The case where the energy is always shared equally would best be described as a strictly simultaneous mechanism, involving the simultaneous stretching of both $X-\mathrm{H}$ bonds beyond the point of dissociation. Data for the two different ions reported here showed that there was a larger degree of equality in energy distribution, more so for $\mathrm{NH}_{2}$ than for $\mathrm{CH}_{2}$, than was observed for $\mathrm{H}_{2} \mathrm{O}$. The role of the stretching modes on these surfaces becomes important when considering the dynamics, something concluded by Minaev and Larsson [64], as well as from the work of van Hemert's group [58], in their studies of $\mathrm{CH}_{2}$. Their conclusions would then suggest a more equal energy distribution than is observed. However, the theoretical calculations also showed for these surfaces that angular motion between bent and linear geometries is practically barrierless, so that bending modes of the molecule will play a role in the dynamics. A combination of bend and stretch motion could introduce radical differences in the length of the C-H bonds, as the torque on the molecule becomes important. These, and similar, effects could explain the experimental observations.

Relevant theoretical data are available for $\mathrm{NH}_{2}$. It is important to note that, unlike $\mathrm{H}_{2} \mathrm{O}$ and $\mathrm{CH}_{2}$, the production of $\mathrm{H}_{2}$ in the DR reaction is almost nonexistent. There are a significant number of events which dissociate from states having a small angle geometry, somehow preferring close $\mathrm{H}-\mathrm{H}$ emission, and this could indicate that additional effects need to be considered. The ground state of $\mathrm{NH}_{2}^{+}$is triplet in character and spin conservation strictly does not forbid $\mathrm{H}_{2}$ to be formed in the singlet bound state. This leads to the possibility that doublet states are more prominent in the initial capture step. If the system then finds itself on a bent doublet surface the formation of a bound $\mathrm{H}_{2}$ molecule is highly unlikely and the production of $\mathrm{NH}+\mathrm{H}$ and $\mathrm{N}+2 \mathrm{H}$ is more favored. When compared to $\mathrm{H}_{2} \mathrm{O}$ and $\mathrm{CH}_{2}$, the channel which benefits from the lack of a favorable $\mathrm{N}+\mathrm{H}_{2}$ dissociative pathway is that leading to $\mathrm{NH}+\mathrm{H}$ rather than $\mathrm{N}+2 \mathrm{H}$. It could then be the case that in a bent configuration, the repulsion between the hydrogen atoms leads to a difference in the stretching modes, with one bond stretched more than the other. This would have the consequence that the production of $\mathrm{NH}+\mathrm{H}$ would be more favored but may also lead, in the three-body channel, to a spread in the $\mathrm{H}$ atom kinetic energies. For both $\mathrm{CH}_{2}$ and $\mathrm{NH}_{2}$ it is clear that the reaction is not a symmetric mechanism but, like $\mathrm{H}_{2} \mathrm{O}$, is best described by an asynchronous concerted mechanism.

\section{CONCLUSIONS}

The fragmentation of the amidogen $\left(\mathrm{NH}_{2}\right)$ and methylene $\left(\mathrm{CH}_{2}\right)$ radicals has been studied via the process of dissociative recombination (DR). In particular, the three-body breakup of these molecules, the most dominant DR reaction channel, has been investigated. Data on the chemical branching of $\mathrm{NH}_{2}$ indicate that this molecule behaves differently than $\mathrm{CH}_{2}$, as well as $\mathrm{H}_{2} \mathrm{O}$ and other small polyatomic $X_{2}$ molecules. This is shown in the almost nonexistent $\mathrm{N}+\mathrm{H}_{2}$ product channel, the similar channel being populated at $\approx 10 \%$ in the DR of other $X_{2}$ molecules. The ground state of $\mathrm{NH}_{2}^{+}$is triplet in character, and spin conservation allows the formation of a bound singlet $\mathrm{H}_{2}$. As such, it might be the case that doublet states play the largest role in the initial capture step. Furthermore, the dynamics of the initial capture plays a large role in the reaction and the process cannot be considered to be entirely statistical in nature.

Comparison of the three-body fragmentation dynamics of the two systems studied here with those of water also show that these molecules behave very differently. $\mathrm{CH}_{2}$ is observed to dissociate with an open-angle geometry, much like the geometry of the ionic and neutral ground states. $\mathrm{NH}_{2}$ and $\mathrm{H}_{2} \mathrm{O}$ dissociate from both open- and closed-angle geometries, differing from the geometries of the ionic and ground states. The partitioning of the available kinetic energy between the hydrogen atom fragments has also been investigated, and the systems also show significant differences. $\mathrm{NH}_{2}$ is observed to fragment with a more equal sharing of the reaction energy, while $\mathrm{CH}_{2}$ and $\mathrm{H}_{2} \mathrm{O}$ show a greater degree of randomization of the reaction energy, with the energy distribution observed for $\mathrm{H}_{2} \mathrm{O}$ being completely random. It is worth noting that as the ion ground state moves away from a linear geometry, the product $\mathrm{H}$ atom energy distribution becomes more random. The competition between the available three-body fragmentation channels also shows differences, with $\mathrm{CH}_{2}$ and $\mathrm{NH}_{2}$ observed to populate equally the channels producing the ground state $\left[\mathrm{C}\left({ }^{3} P\right), \mathrm{N}\left({ }^{4} S\right)\right]$ and first excited state $\left[\mathrm{C}\left({ }^{1} D\right), \mathrm{N}\left({ }^{2} D\right)\right]$ heavy atoms, while $\mathrm{H}_{2} \mathrm{O}$ showed a factor of 3 preference to populate the channel producing the ground state $\mathrm{O}\left({ }^{3} P\right)$ rather than first excited state $\mathrm{O}\left({ }^{1} D\right)$ atoms. Simple models based on the electronic degeneracy of the available products have been suggested to predict such populations of DR product channels, i.e., purely statistical models. The first was used to predict the three-body population channels for $\mathrm{H}_{2} \mathrm{O}$ [25] and the second to predict the fragmentation of $\mathrm{NO}^{+}$[43]. The model for $\mathrm{H}_{2} \mathrm{O}$ correctly predicted the factor of 3 preference for ground-state oxygen atoms and the model used for NO also gave a good agreement with the experimental data. However, both models fail to predict the observed branching for $\mathrm{CH}_{2}$ and $\mathrm{NH}_{2}$. This leads to the conclusion that the prediction for $\mathrm{H}_{2} \mathrm{O}$ was probably fortuitous. As with $\mathrm{H}_{2} \mathrm{O}$, there is a general lack of information related to the three-body dynamics on the potential-energy surfaces (PESs) involved in the DR reaction, especially those in the high-energy region close to the ionization region. However, the observations made from the modeling on $\mathrm{H}_{2} \mathrm{O}$ with known PESs indicated that the dynamics occurring on these surfaces played a significant role in the DR process, especially in the regions of avoided crossings/conical intersections.

All of the observations made from the DR experiments, both the general and the detailed three-body breakup, together with what we learned from the modeling of $\mathrm{H}_{2} \mathrm{O}$ and what is known about the potential-energy surfaces for all of these molecules leads to the conclusion that even though such systems are very similar in nature, they display very dissimilar DR reaction dynamics. This suggests that finding a simple, system-independent theory to describe all of the aspects of the DR reaction may not be so simple after all. 


\section{ACKNOWLEDGMENTS}

We would like to thank the CRYRING staff at the Manne Siegbahn Laboratory for their tireless work and excellent support. We would also like to thank Stephan Schlemmer for some valuable discussions. This work was supported by the Swedish Research Council, the Swedish Foundation for International Cooperation in Research and Higher Education.
R.T. was funded under the IHP Programme of the EC under Contract No. HPRN-CT-2000-00142. The work of W.J.vdZ. is part of the research of the "Stichting voor Fundamenteel Onderzoek der Materie," made possible by financial support by the Stichting voor Wetenschappelijk Onderzoek. The Oak Ridge collaboration is sponsored by the U.S. Department of Energy, Office of Basic Energy Sciences, Division of Chemical Sciences under Contract No. DE-AC05-00OR22725 with UT-Battelle, LLC.
[1] J. A. Cardelli, D. M. Meyer, M. Jura, and B. D. Savage, Astrophys. J. 467, 334 (1996).

[2] B. J. McCall, A. J. Huneycutt, R. J. Saykally, T. R. Gebale, N. Djurić, G. H. Dunn, J. Semaniak, O. Novotny, A. Al-Khalili, A. Ehlerding, F. Hellberg, S. Kalhori, A. Neau, R. Thomas, F. Österdahl, and M. Larsson, Nature (London) 422, 500 (2003).

[3] E. Herbst and W. Klemperer, Astrophys. J. 185, 505 (1973).

[4] W. D. Watson, Astrophys. J. 183, L17 (1973).

[5] R. P. Wayne, Chemistry of Atmospheres, Second Edition, (Oxford Science Publications, Oxford, 1991), pp. 357-367.

[6] G. Herzberg and D. A. Ramsey, J. Chem. Phys. 20, 347 (1952).

[7] K. Dressler and D. A. Ramsey, Philos. Trans. R. Soc. London, Ser. A 251, 553 (1959).

[8] G. F. Mitchell, S. S. Prasad, and W. T. Huntress, Astrophys. J. 244, 1087 (1981).

[9] S. Wyckoff, S. C. Tegler, and L. Engel, Astrophys. J. 368, 279 (1991).

[10] S. C. Tegler, L. F. Burke, S. Wyckoff, M. Womack, U. Fink, and M. DiSanti, Astrophys. J. 384, 292 (1992).

[11] E. F. van Dishoeck, D. J. Jansen, P. Schilke, and T. G. Phillips, Astrophys. J. Lett. 416, L83 (1993).

[12] H. Biehl, G. Schönnenbeck, F. Stuhl, and V. Staemmler, J. Chem. Phys. 101, 3819 (1994).

[13] P. D. Feldman, K. B. Fournier, V. P. Grinin, and A. M. Zvereva, Astrophys. J. 404, 348 (1993).

[14] D. M. Meyer and K. C. Roth, Astrophys. J. Lett. 376, L49 (1991).

[15] R. M. Haberli, M. R. Combi, T. I. Gombosi, D. L. de Zeeuw, and K. G. Powell, Icarus 130, 373 (1997).

[16] E. Herbst, Annu. Rev. Phys. Chem. 46, 27 (1995).

[17] E. Herbst and H.-H. Lee, Astrophys. J. 485, 689 (1997).

[18] M. Larsson, in Advances in Gas Phase Ion Chemistry, edited by N. G. Adams and L. M. Babcock (JAI Press Inc./Elsevier Science B. V., USA, 2001), Vol. 4, p. 179.

[19] M. Larsson, in The Encyclopedia of Mass Spectrometry. Volume 1 Theory and Ion Chemistry, edited by P. B. Armentrout, M. L. Gross, and R. Caprioli (Elsevier Ltd, UK, 2003), p. 195.

[20] D. Zajfman, Z. Amitay, C. Broude, P. Forck, B. Seidel, M. Grieser, D. Habs, D. Schwalm, and A. Wolf, Phys. Rev. Lett. 75, 814 (1995).

[21] W. J. van der Zande, J. Semaniak, V. Zengin, G. Sundström, S. Rosén, C. Strömholm, S. Datz, H. Danared, and M. Larsson, Phys. Rev. A 54, 5010 (1996).

[22] J. R. Peterson, A. Le Padellec, H. Danared, G. H. Dunn, M. Larsson, Å. Lason, R. Peverall, C. Strömholm, S. Rosén, M. af
Ugglas, and W. J. van der Zande, J. Chem. Phys. 108, 1978 (1998).

[23] R. Peverall, S. Rosén, M. Larsson, J. R. Peterson, R. Bobbenkamp, S. L. Guberman, H. Danared, M. af Ugglas, A. AlKhalili, A. N. Maurellis, and W. J. van der Zande, Geophys. Res. Lett. 27, 481 (2000).

[24] S. Datz, R. Thomas, S. Rosén, M. Larsson, A.M. Derkatch, F. Hellberg, and W. van der Zande, Phys. Rev. Lett. 85, 5555 (2000).

[25] R. Thomas, S. Rosén, F. Hellberg, A. Derkatch, M. Larsson, S. Datz, R. Dixon, and W. J. van der Zande, Phys. Rev. A 66, 032715 (2002).

[26] D. R. Bates, Astrophys. J. 306, L45 (1986).

[27] D. R. Bates, J. Phys. B 24, 3267 (1991).

[28] S. Datz, G. Sundström, Ch. Biedermann, L. Broström, H. Danared, S. Mannervik, J. R. Mowat, and M. Larsson, Phys. Rev. Lett. 74, 896 (1995).

[29] Å. Larson, A. Le Padellec, J. Semaniak, C. Strömholm, M. Larsson, S. Rosén, R. Peverall, H. Danared, N. Djurić, G. H. Dunn, and S. Datz, Astrophys. J. 505, 459 (1998).

[30] L. Vikor, A. Al-Khalili, H. Danared, N. Djurić, G. H. Dunn, M. Larsson, A. Le Padellec, S. Rosén, and M. af Ugglas, Astron. Astrophys. 344, 1027 (1999).

[31] S. Rosén, A. Derkatch, J. Semaniak, A. Neau, A. Al-Khalili, A. Le Padellec, L. Vikor, R. Thomas, H. Danared, M. af Ugglas, and M. Larsson, Faraday Discuss. 115, 295 (2000).

[32] M. Larsson and R. Thomas, Phys. Chem. Chem. Phys. 3, 4471 (2001).

[33] R. N. Dixon, D. W. Hwang, X. F. Yang, S. Harich, J. J. Lin, and X. Yang, Science 285, 1249 (1999).

[34] D. Strasser, J. Levin, H. B. Pedersen, O. Heber, A. Wolf, D. Schwalm, and D. Zajfman, Phys. Rev. A 65, 010702(R) (2005).

[35] J. Dyke (private communication).

[36] http://webbook.nist.gov/

[37] A. Neau, A. Al Khalili, S. Rosén, A. Le Padellec, A. M. Derkatch, W. Shi, L. Vikor, M. Larsson, J. Semaniak, R. Thomas, N. B. Någård, K. Andersson, H. Danared, and M. af Ugglas, J. Chem. Phys. 113, 1762 (2000).

[38] K. H. Berkner, T. J. Morgan, R. V. Pyle, and J. W. Stearns, in Proceedings of the Seventh International Conference on the Physics of Electronic and Atomic Collisions, Amsterdam, 1971. Abstracts, edited by J. Kistermaker (North-Holland, Amsterdam, 1971), p. 422.

[39] Buckbee-Mears Co., Minneapolis, MN.

[40] Z. Amitay and D. Zajfman, Rev. Sci. Instrum. 68, 1387 
(1997).

[41] T. Graber, E. P. Kanter, J. Levin, D. Zajfman, Z. Vager, and R. Naaman, Phys. Rev. A 56, 2600 (1997).

[42] A. Baer, M. Grieser, L. Knoll, J. Levin, R. Repnow, D. Schwalm, Z. Vager, R. Wester, A. Wolf, and D. Zajfman, Phys. Rev. A 59, 1865 (1999).

[43] F. Hellberg, S. Rosén, R. Thomas, A. Neau, M. Larsson, A. Petrignani, and W. J. van der Zande, J. Chem. Phys. 118, 6250 (2003).

[44] B. J. McCall, A. J. Huneycutt, R. J. Saykally, N. Djurić, G. H. Dunn, J. Semaniak, O. Novotny, A. Al-Khalili, A. Ehlerding, F. Hellberg, S. Kalhori, A. Neau, R. Thomas, A. Paal, F. Österdahl, and M. Larsson, Phys. Rev. A (to be published)

[45] Y. Kabbadj, T. R. Huet, D. Uy, and T. Oka, J. Mol. Spectrosc. 175, 277 (1996).

[46] G. Herzberg, Molecular Spectra and Molecular Structure. II: Infrared and Raman Spectra of Polyatomic Molecules (Krieger Publishing Company, Reprint Edition w/corrections 1991), p. 49, and Chap. 1 discussing rotation in detail.

[47] A. Al-Khalili, S. Rosén, 1 H. Danared, A. M. Derkatch, A. Källberg, M. Larsson, A. Le Padellec, A. Neau, J. Semaniak, R. Thomas, M. af Ugglas, L. Vikor, W. Zong, W. J. van der Zande, X. Urbain, M. J. Jensen, R. C. Bilodeau, O. Heber, H. B. Pedersen, C. P. Safvan, L. H. Andersen, M. Lange, J. Levin, G. Gwinner, L. Knoll, M. Scheffel, D. Schwalm, R. Wester, D. Zajfman, and A. Wolf, Phys. Rev. A 68, 042702 (2003).

[48] W. J. van der Zande, in Proceedings of the 1999 Conference on Dissociative Recombination: Theory, Experiment and Application IV, Stockholm, Sweden, 1999, edited by M. Larsson, J. B. A. Mitchell, and I. F. Schneider (World Scientific, Singapore,
2000), p. 251.

[49] T. G. Slanger and G. Black, J. Chem. Phys. 77, 2432 (1982).

[50] R. Brandi, E. Leonardi, and C. Petrongolo, J. Phys. Chem. A 101, 5696 (1997).

[51] J. C. Stephens, Y. Yamaguchi, and H. F. Schaefer III, J. Mol. Struct.: THEOCHEM 461-462, 41 (1999).

[52] Y. Yamaguchi, B. C. Hoffman, J. C. Stephens, and H. F. Schaefer III, J. Phys. Chem. A 103, 7701 (1999).

[53] P. Jensen, T. E. Odaka, W. P. Kraemer, T. Hirano, and P. R. Bunker, Spectrochim. Acta, Part A 58, 763 (2002).

[54] R. A. Beärda, M. C. van Hemert, and E. F. van Dishoeck, J. Chem. Phys. 97, 8240 (1992).

[55] G-J. Kroes, E. F. van Dishoeck, R. A. Beärda, and M. C. van Hemert, J. Chem. Phys. 99, 228 (1993).

[56] R. A. Beärda, G-J. Kroes, M. C. van Hemert, B. Heumann, R. Schinke, and E. F. van Dishoeck, J. Chem. Phys. 100, 1113 (1994).

[57] G. J. Kroes and M. C. van Hemert, J. Chem. Phys. 100, 1128 (1994).

[58] R. A. Beärda, M. C. van Hemert, and E. F. van Dishoeck, J. Chem. Phys. 102, 8930 (1995).

[59] G-J. Kroes, M. C. van Hemert, G. D. Billing, and D. Neuhauser, Chem. Phys. Lett. 271, 311 (1997).

[60] G-J. Kroes, M. C. van Hemert, G. D. Billing, and D. Neuhauser, J. Chem. Phys. 107, 5757 (1997).

[61] D. R. Yarkony, Rev. Mod. Phys. 68, 985 (1996).

[62] D. R. Yarkony, J. Chem. Phys. 104, 2932 (1996).

[63] N. Matsunaga and D. R. Yarkony, J. Chem. Phys. 107, 7825 (1997).

[64] B. Minaev and M. Larsson, Chem. Phys. 280, 15 (2002). 